\title{
Long Non-Coding RNAs As Potential Novel Prognostic Biomarkers in Colorectal Cancer
}

\begin{abstract}
Ester Saus ${ }^{1,2+}$, Anna Brunet-Vega ${ }^{3 \dagger}$, Susana Iraola-Guzmán ${ }^{1,2+}$, Cinta Pegueroles ${ }^{1,2}$, Toni Gabaldón ${ }^{1,2,4 *}$ and Carles Pericay ${ }^{3,5 * \neq}$

${ }^{1}$ Centre for Genomic Regulation, The Barcelona Institute of Science and Technology, Barcelona, Spain, ${ }^{2}$ Universitat Pompeu Fabra, Barcelona, Spain, ${ }^{3}$ Department of Oncology Research, Parc Tauli Foundation, Corporació Sanitària Parc Taulí University Institute - UAB Barcelona, Sabadell, Spain, ${ }^{4}$ Institució Catalana de Recerca i Estudis Avançats, Barcelona, Spain, ${ }^{5}$ Oncology Service, Hospital de Sabadell, Corporació Sanitària Parc Taulí - University Institute - UAB Barcelona, Sabadell, Spain
\end{abstract}

OPEN ACCESS

Edited by:

Margaret Jane Currie,

University of Otago, Christchurch,

New Zealand

Reviewed by:

Ulf Andersson Ørom,

Max Planck Institute for Molecular

Genetics, Germany

Mohammadreza Hajjari,

Shahid Chamran University of Ahvaz,

Iran

*Correspondence:

Toni Gabaldon

toni.gabaldon@crg.eu;

Carles Pericay

cpericay@gmail.com

${ }^{\dagger}$ These authors have contributed equally to this work.

${ }^{\text {F}}$ Senior authorship.

Specialty section: This article was submitted to

Cancer Genetics,

a section of the journal

Frontiers in Genetics

Received: 13 November 2015 Accepted: 21 March 2016

Published: 12 April 2016

Citation:

Saus E, Brunet-Vega A, Iraola-Guzmán S, Pegueroles $C$,

Gabaldón T and Pericay C (2016) Long Non-Coding RNAs As Potential Novel Prognostic Biomarkers in Colorectal Cancer. Front. Genet. 7:54. doi: 10.3389/fgene.2016.00054
Colorectal cancer $(\mathrm{CRC})$ is the fourth most common cause of death worldwide. Surgery is usually the first line of treatment for patients with $\mathrm{CRC}$ but many tumors with similar histopathological features show significantly different clinical outcomes. The discovery of robust prognostic biomarkers in patients with $\mathrm{CRC}$ is imperative to achieve more effective treatment strategies and improve patient's care. Recent progress in next generation sequencing methods and transcriptome analysis has revealed that a much larger part of the genome is transcribed into RNA than previously assumed. Collectively referred to as non-coding RNAs (ncRNAs), some of these RNA molecules such as microRNAs (miRNAs) and long non-coding RNAs (IncRNAs) have been shown to be altered and to play critical roles in tumor biology. This discovery leads to exciting possibilities for personalized cancer diagnosis, and therapy. Many IncRNAs are tissue and cancer-type specific and have already revealed to be useful as prognostic markers. In this review, we focus on recent findings concerning aberrant expression of IncRNAs in CRC tumors and emphasize their prognostic potential in CRC. Further studies focused on the mechanisms of action of IncRNAs will contribute to the development of novel biomarkers for diagnosis and disease progression.

Keywords: long non-coding RNA, ncRNA, prognostic marker, colorectal cancer, biomarker

\section{INTRODUCTION}

\section{Need for Prognostic Markers in Colorectal Cancer}

Colorectal cancer (CRC) is among the most commonly diagnosed cancers worldwide. In 2012, according to the GLOBOCAN estimations, there were 1.3 million new cases of CRC worldwide (Ferlay et al., 2015). That year, around 694,000 patients died of the disease, accounting for $8.5 \%$ of all cancer deaths, and ranking CRC the fourth most common cause of death from cancer. Colorectal cancer develops as a result of the pathologic transformation of normal colonic epithelium to adenomatous polyp, which ultimately leads to invasive cancer (Jass, 2006). Tumor induction and progression is considered a stepwise process with the accumulation of different genetic and epigenetic alterations. Most tumors (85\%) are generated by chromosomal instability and are associated with high frequency aneuploidy and allelic imbalance. The prognosis and survival of CRC patients are clearly related to the degree of penetration of the tumor through the bowel 
wall, and to the presence or absence of nodal involvement and distant metastases. The American Joint Committee on Cancer's TNM (Tumor size, lymph Node involvement, and distant Metastasis) staging system is the current standard for determining the prognosis of patients with CRC. After diagnosis, staging (stages I to IV) is performed based on the extent of penetration of the colorectal cancer into the layers forming the wall of the colon and whether the tumor cells have spread to lymph nodes and other organs. This classification is important for planning patient treatment. The gold standard therapy for resectable tumors is surgery, whereas adjuvant chemotherapy is indicated only in patients with a high risk of disease recurrence. Traditional prognostic factors for malignancy include clinical and pathological criteria such as patient's age, tumor size, and tumor grade, number of affected local lymph nodes, and presence and grade of metastasis. Although these factors have been used for decades, they have serious limitations in predicting patient outcome (Burke, 2004). In stage II the tumor is confined to the bowel wall in contrast to stage III and IV, in which the tumors have disseminated to local lymph nodes and distant organs, respectively. The majority of patients with stage II do not receive adjuvant chemotherapy treatment since, at present there is no evidence for beneficial effect for this patient group as a whole. From all those patients receiving treatment, only a small proportion (1-5\%) derives clinical benefit, whereas adverse side effects are common (Aranha and Benson, 2007). Nevertheless, $20-25 \%$ of all stage II CRC patients will present with recurrent disease and subsequent death from disease within 5 years after primary surgery (Benson et al., 2004). On the other hand, adjuvant treatment is universally recommended for all patients with stage III disease, for whom the cancer has already spread to the surrounding lymph nodes.

Thus, there is a need to add prognostic and predictive markers to the current staging system. In the last two to three decades, hundreds of cancer biological prognostic markers for CRC cancer have been proposed such as, microsatellite instability (Popat et al., 2005), chromosomal instability (Pino and Chung, 2010), Kras mutation (Rui et al., 2013), mRNA and microRNA expression profile (Nugent et al., 2011; Salazar et al., 2011; Sanz-Pamplona et al., 2012). Although they have shown a potential in this field, validation studies are still required and, to date, there is insufficient evidence to recommend the routine clinical use of any of these putative biomarkers. Therefore, the discovery of robust prognostic and/or predictive biomarkers in patients with CRC is imperative for advancing treatment strategies for the disease and improving patient care.

In this review, we provide an overview of recent findings concerning the prognostic potential of lncRNAs in CRC.

\section{LncRNAs in Cancer and Their Potential As Prognostic Biomarkers}

Recent progress in next generation sequencing methods and in transcriptome analysis has shown that a much larger portion of the genome is transcribed into RNA than previously assumed (Consortium, 2012). Long non-coding RNAs (lncRNAs) are a widespread class of expressed RNA transcripts longer than 200 nucleotides, that have no coding potential but that, similar to protein coding genes, are typically polyadenylated, transcribed by RNA polymerase II, and spliced (Ponting et al., 2009; Ulitsky and Bartel, 2013). Compared to protein-coding genes, they are expressed at lower levels and in a more tissue-specific manner (Derrien et al., 2012). Initially, IncRNAs were thought to be simply the result of transcriptional noise, but recent studies point to a crucial involvement of a growing number of lncRNAs in central cellular processes such as epigenetic modulation, transcription, and translation (Mercer and Mattick, 2013; Johnsson et al., 2014). During the last decade, the rapid advance in sequencing and array technologies has further facilitated the study of these molecules regarding their involvement in pathological processes. In this context, recent studies show a clear implication of some lncRNAs in the development of various diseases, ranging from neurodegeneration to cancer (Wapinski and Chang, 2011).

Recent large-scale sequencing efforts such as the International Cancer Genomics Consortium and the Cancer Genome Atlas, as well as numerous small-scale projects, have focused on the detection of somatic genetic and epigenetic alterations that are tightly associated with the disease. These studies have revealed that a significant fraction of such alterations lie in noncoding parts of the genome, often affecting lncRNA loci. Such alterations can involve deletions, differences in copy number, point mutations but also regulatory changes that can lead through different modes of action to changes in gene expression. For example, MALAT1, a lncRNA with an important role in cell proliferation, migration and invasion, has been found significantly up-regulated in several cancers, including lung, breast, prostate, liver, and colon. Many cancer-relevant genes, in particular tumor suppressor genes, encompass long antisense ncRNAs (Nie et al., 2012), and some evolutionarily conserved non-coding transcripts are altered in human cancer, such as leukemia and other carcinomas (Calin et al., 2007). The finding that alterations in sequence or expression of some lncRNAs might be associated to specific stages of cancer progression paves the way for their use as prognostic biomarkers (Hu et al., 2014).

Several studies have indicated dysregulation of lncRNA expression in CRC tumors and a potential functional impact in pathogenesis and clinical implications. These studies are quite heterogeneous, including association studies in large-scale sequencing projects as well as detailed analyses of the direct involvement of particular lncRNAs in the progression of the disease. Overall, the precise molecular mechanisms underlying CRC pathogenesis remain to be fully elucidated, with still a limited number of lncRNAs with a well-characterized molecular mechanism of action. The review of these few known molecular mechanisms is beyond the scope of this paper, and we direct the interested reader to recent reviews in that topic (Gutschner and Diederichs, 2012; Zhang K. et al., 2014). Besides, there are a growing number of new lncRNAs with unknown functions, and whose implications in tumor biology are not fully understood. For instance, a recent study based on 7256 RNA-seq libraries from tumors, normal tissues and cell lines, identified a total of 196 non-coding transcripts associated with CRC, but the vast majority of them (163) were previously unknown (Iyer 
et al., 2015). Imbalances in expression levels may be used to identify new potential markers for disease progression. However, further analyses will be needed to address whether alterations in sequence or expression of some lncRNAs are involved in special biological processes relevant to cancer.

In the present review, we focus on studies investigating whether lncRNAs can serve as prognostic biomarkers for CRC (Table 1; Figure 1), and we will discuss recent advances in the potential value of lncRNAs to predict outcomes of CRC patients (Table 2). The candidate lncRNAs reviewed below may add prognostic power to the current gold-standard AJCC (American Joint Committee on Cancer) staging system.

\section{ONCOGENIC LnCRNAs ASSOCIATED WITH PROGNOSIS IN COLORECTAL CANCER}

\section{H}

The "H19 antisense long, non-coding RNA" $91 \mathrm{H}$ is a $120 \mathrm{~kb}$ antisense long non-coding transcript spanning the H19 gene locus. $91 \mathrm{H}$ expression has been associated with breast cancer (Berteaux et al., 2008) and esophageal squamous cell carcinoma progression (Gao et al., 2015). Deng et al. (2014) found $91 \mathrm{H}$ transcript over-expression in CRC tissues compared with adjacent non-cancerous tissue, as well as CRC cell lines compared with normal intestinal epithelial cell line. The authors showed that in vitro knockdown of $91 \mathrm{H}$ inhibited cell motility, migration and invasiveness of CRC cells lines. Finally, they observed that elevated expression of $91 \mathrm{H}$ was associated with poor prognosis and distant metastasis in patients with CRC (Deng et al., 2014).

\section{CCAT1}

Colon Cancer Associated Transcript-1 (CCAT1) was first described as an $11.88 \mathrm{~kb}$ lncRNA highly expressed in CRC compared to normal tissue (Nissan et al., 2012). CCAT1 is transcribed from a locus in chromosome 8q24.21, located $515 \mathrm{~kb}$ upstream of the well-known transcription factor $c-M y c$, and reported to be a "hot-spot" locus with many genetic alterations in colorectal cancer (Zanke et al., 2007; Haerian et al., 2011). Recently, Qiu and Yan (2015) analyzed a cohort of five published datasets including 355 samples, validating the association of CCAT1 with CRC (Qiu and Yan, 2015). CCAT1 up-regulation is present in the vast majority of primary CRC tumors, including pre-cancerous polyps (adenomas), lymph nodes, blood, and distant CRC metastasis. Increased expression of CCAT1 has been correlated with patient's clinical stage, lymph node metastasis, and survival time. Taking the information together, it suggests that CCAT1 could have key roles in both tumorigenesis and metastasis, and thus it may be a good candidate as a clinical outcome biomarker (Alaiyan et al., 2013; He et al., 2014). Indeed, a recent study showed that CCAT1 levels were not only significantly higher in plasma of CRC patients compared to control individuals but also significantly decreased in CRC patients after surgical treatment (Zhao et al., 2015). The authors established by means of ROC analysis that plasma CCAT1 provided a strong separation between CRC patients and the control group (AUC $=0.836, P<0.001)$, an effective screening which improved when combining plasma levels of CCAT1 and HOTAIR (AUC $=0.954, P<0.001$ ). In addition, this combination of CCAT1 and HOTAIR levels in plasma could detect CRC at an early stage (85\%), demonstrating that increased plasma levels of CCAT1 (especially when combined with HOTAIR) could be used as a predictive biomarker for CRC screening (Zhao et al., 2015).

\section{CLMAT3}

Cancer Liver Metastasis Associated Transcript-3 (CLMAT3) is a long non-coding RNA that recently emerged as a potential independent prognostic factor in CRC with liver metastasis (Ye et al., 2015). Almost half of the CRC patients with advanced CRC will suffer colorectal liver metastasis during the disease course, and so far there are no available early prognostic biomarkers that enable the screening of CRC patients suffering liver metastasis. To that end, a new study aimed to profile the expression levels of lncRNAs in a total of 264 CRC samples with or without liver metastasis (synchronous and metachronous). First, the authors identified 40 lncRNAs differentially expressed in the discovery phase. Next, they validated three novel lncRNAs (TR140014124, TR01015341, and TR05005298, further termed CLMAT1 to 3 respectively) by RT-qPCR in an independent cohort. Finally, they found that IncRNA CLMAT3 located in chromosome 14 (chr14:101379770-101381326, Hg19) was the most up-regulated lncRNA and that its high expression was significantly associated with liver metastasis and lymph node metastasis. In addition, the patients with tumors displaying high IncRNA-CLMAT3 expression exhibited shorter overall survival than those with low lncRNA-CLMAT3 expression tumors. Furthermore, the results of multivariate analysis indicated that lncRNA-CLMAT3 expression was an independent prognostic indicator of CRC patient's survival compared with CRC patients with liver metastasis (Ye et al., 2015). However, these results need to be proven in a larger cohort, including a heterogeneous population, and whose 5-year overall survival rate is confirmed.

\section{DANCR}

Differentiation Antagonizing Non-Protein Coding RNA (DANCR) is a 7.94 RNA gene, mapping on chr4q12, and associated to stem cell-like state. It has been shown to be involved in maintenance of undifferentiated cell state of epidermis (Kretz et al., 2012) and osteoblasts (Zhu and Xu, 2013; Jia et al., 2015). Two recent studies suggest a novel mechanism of tumorigenesis involving this lncRNA in hepatocellular carcinoma (Yuan et al., 2016) and in colorectal cancer (Liu et al., 2015), respectively. The former shows that DANCR action may increase stemness features and offer a potential prognostic marker and a therapeutic target for hepatocellular carcinoma. The latter quantifies the expression of lncRNA DANCR in a total of 104 CRC tissues and adjacent non-tumor tissues by qRT-PCR, and analyzes the correlation with the clinicopathological characteristics and outcome of the CRC patients included in the study. As a result, the authors show a remarkably higher expression of lncRNA DANCR in CRC tissues compared with adjacent non-tumor tissues $(P<0.05)$, and show that these values are significantly associated with TNM stage, histologic grade and lymph node metastasis $(P<0.05)$, 
TABLE 1 | Description of potential prognostic IncRNA markers in colorectal cancer.

\begin{tabular}{|c|c|c|c|c|c|c|}
\hline LncRNA & Genomic location & Gene size (kb) & Locus & Type & $\begin{array}{l}\text { Function in tumorigenesis of CRC and } \\
\text { mechanism of action }\end{array}$ & References \\
\hline \multicolumn{7}{|c|}{ ONCOGENIC InCRNA } \\
\hline $91 H$ & Chr11p15 & 119.32 & H19/IGF2 & AS & Proliferation, migration and invasion. & Deng et al., 2014 \\
\hline CCAT1 & Chr8q24.21 & 11.88 & $c-M Y C$ & - & $\begin{array}{l}\text { Progression and metastasis mediated by c-Myc } \\
\text { binding to CCAT1 promoter region. }\end{array}$ & $\begin{array}{l}\text { Nissan et al., 2012; Alaiyan } \\
\text { et al., 2013; He et al., 2014; } \\
\text { Zhao et al., } 2015\end{array}$ \\
\hline CLMAT3 & Chr14q32.31 & 1.55 & SPARC & - & Progression and metastasis. & Ye et al., 2015 \\
\hline DANCR & Chr4q12 & 7.94 & - & - & Progression and metastasis. & Liu et al., 2015 \\
\hline FEZF1-AS1 & Chr7q31.32 & 6.42 & FEZF1 & AS & $\begin{array}{l}\text { Proliferation, migration and invasion through } \\
\text { S-phase entry. }\end{array}$ & Chen et al., 2016 \\
\hline FTX & ChrXq13.2 & 329.62 & $X I C$ & lincRNA & $\begin{array}{l}\text { Proliferation, migration, and invasion mediated } \\
\text { by Xist up-regulation. }\end{array}$ & Guo X. B. et al., 2015 \\
\hline HOTAIR & Chr12q13.13 & 12.64 & HOXC & AS & $\begin{array}{l}\text { Migration, and invasion through } \\
\text { Polycomb-mediated chromatin modifications, } \\
\text { and EMT molecules interaction. }\end{array}$ & $\begin{array}{l}\text { Rinn et al., 2007; Kogo et al., } \\
\text { 2011; Wu Z. H. et al., 2014; } \\
\text { Zhang S. et al., 2014; Zhao } \\
\text { et al., } 2015\end{array}$ \\
\hline HOTTIP & Chr7p15.2 & 8.68 & HoxA & AS & $\begin{array}{l}\text { Progression and metastasis through G1 phase } \\
\text { arrest, S phase reduction, and apoptosis } \\
\text { promotion through p21 inactivation. }\end{array}$ & $\begin{array}{l}\text { Ren et al., 2015; Lian et al., } \\
2015\end{array}$ \\
\hline IncRNA-ATB & Chr14q11.2 & 2.73 & - & - & $\begin{array}{l}\text { Promotion of invasion and metastasis via } \\
\text { interaction with transcription factors ZEB1 and } \\
\text { ZEB2, involved in EMT in other cancer types. }\end{array}$ & $\begin{array}{l}\text { Yuan et al., 2014; Iguchi et al., } \\
2015\end{array}$ \\
\hline MALAT1 & Chr11q13.1 & 8.75 & NEAT-2 & lincRNA & $\begin{array}{l}\text { Proliferation, migration, and invasion through } \\
\text { release of proto-oncogene PTBP2, and } \\
\text { interaction with AKAP-9 protein, and } \\
\text { Wnt/ } \beta \text {-catenin signaling pathway proteins. }\end{array}$ & $\begin{array}{l}\text { Ji et al., 2013; Smolle et al., } \\
\text { 2014; Ji et al., 2014; Yang } \\
\text { et al., } 2015\end{array}$ \\
\hline PCAT1 & Chr8q24.21 & 173.96 & - & lincRNA & $\begin{array}{l}\text { Potential promotion of metastasis through } \\
\text { interaction with } B R C A 2 \text { and } \mathrm{PRC} 2 \text { in other } \\
\text { cancer types. }\end{array}$ & $\begin{array}{l}\text { Prensner et al., 2011; Ge } \\
\text { et al., } 2013\end{array}$ \\
\hline PVT1 & Chr8q24.21 & 306.72 & PVT1 & lincRNA & $\begin{array}{l}\text { Proliferation, invasion, and antiapoptotic effect } \\
\text { via modulation of chromatin remodeling } \\
\text { complex SWI/SNF. }\end{array}$ & Takahashi et al., 2014 \\
\hline TUG1 & Chr22q12.2 & 9.7 & TUG1 & lincRNA & $\begin{array}{l}\text { Progression and metastasis mediated by } \\
\text { modulation of the expression of EMT related } \\
\text { genes. }\end{array}$ & Sun et al., 2016 \\
\hline UCA1 & Chr19p13.12 & 7.37 & UCA1 & lincRNA & $\begin{array}{l}\text { Proliferation, and antiapoptotic effect through } \\
\text { G0/G1 growth arrest. }\end{array}$ & Han et al., 2014 \\
\hline \multicolumn{7}{|c|}{ TUMOR SUPPRESSIVE IncRNA } \\
\hline GAS5 & Chr1q25.1 & 4.98 & GAS5 & - & $\begin{array}{l}\text { Inhibition of cell proliferation by mimicking } \\
\text { glucocorticoid response element (GRE). }\end{array}$ & $\begin{array}{l}\text { Mourtada-Maarabouni et al., } \\
\text { 2010; Yin et al., } 2014\end{array}$ \\
\hline LINC01296 & Chr22q11.1 & 20.55 & - & lincRNA & Potential epigenetic silencing mechanism. & Qiu and Yan, 2015 \\
\hline MEG3 & Chr14q32.2 & 81.62 & DLK1-MEG3 & lincRNA & $\begin{array}{l}\text { Prevents abnormal proliferation by promoting } \\
\text { p53 expression. }\end{array}$ & $\begin{array}{l}\text { Zhang et al., 2003; Zhou } \\
\text { et al., 2007; Yin et al., } 2015\end{array}$ \\
\hline NcRAN & Chr17q25.1 & 7.58 & SNHG16 & AS & Involved in migration and invasion. & $\begin{array}{l}\text { Qi et al., 2015; Smolle et al., } \\
2014\end{array}$ \\
\hline$n c R u P A R$ & Chr5q13.3 & 0.48 & ncRUPAR & IncRNA & Involved in invasion and metastasis. & Yan et al., 2014 \\
\hline$R P 11-462 C 24.1$ & Chr4q25 & 82.27 & RPL34 & AS & Involved in invasion, and metastasis. & Shi et al., 2014 \\
\hline TUSC7 & Chr3q13.31 & 14.34 & LSAMP & lincRNA & $\begin{array}{l}\text { Growth suppressor through regulation of } \\
\text { apoptotic and cell cycle transcripts in } \\
\text { osteoblasts. No mechanism described in CRC. }\end{array}$ & Qi et al., 2013 \\
\hline
\end{tabular}

Abbreviations: AS, antisense; EMT, Epithelial-mesenchymal transition; lincRNA, long intergenic non-coding RNA.

with no significant correlation with other clinical features such as gender, age, tumor size, and local invasion $(P>0.05)$. Moreover, the authors suggest that lncRNA DANCR expression could be an independent prognostic indicator for overall survival (HR = 2.131, 95\% CI, 1.157-7.058; $P=0.009$ ) and disease-free survival
$(\mathrm{HR}=2.397,95 \% \mathrm{CI}, 1.385-7.279 ; P=0.006)$ in patients with colorectal cancer. Thus, lncRNA DANCR up-regulation is associated with aggressive progression and poor prognosis in colorectal cancer and may function as an independent marker for predicting the clinical outcome of colorectal cancer patients. 


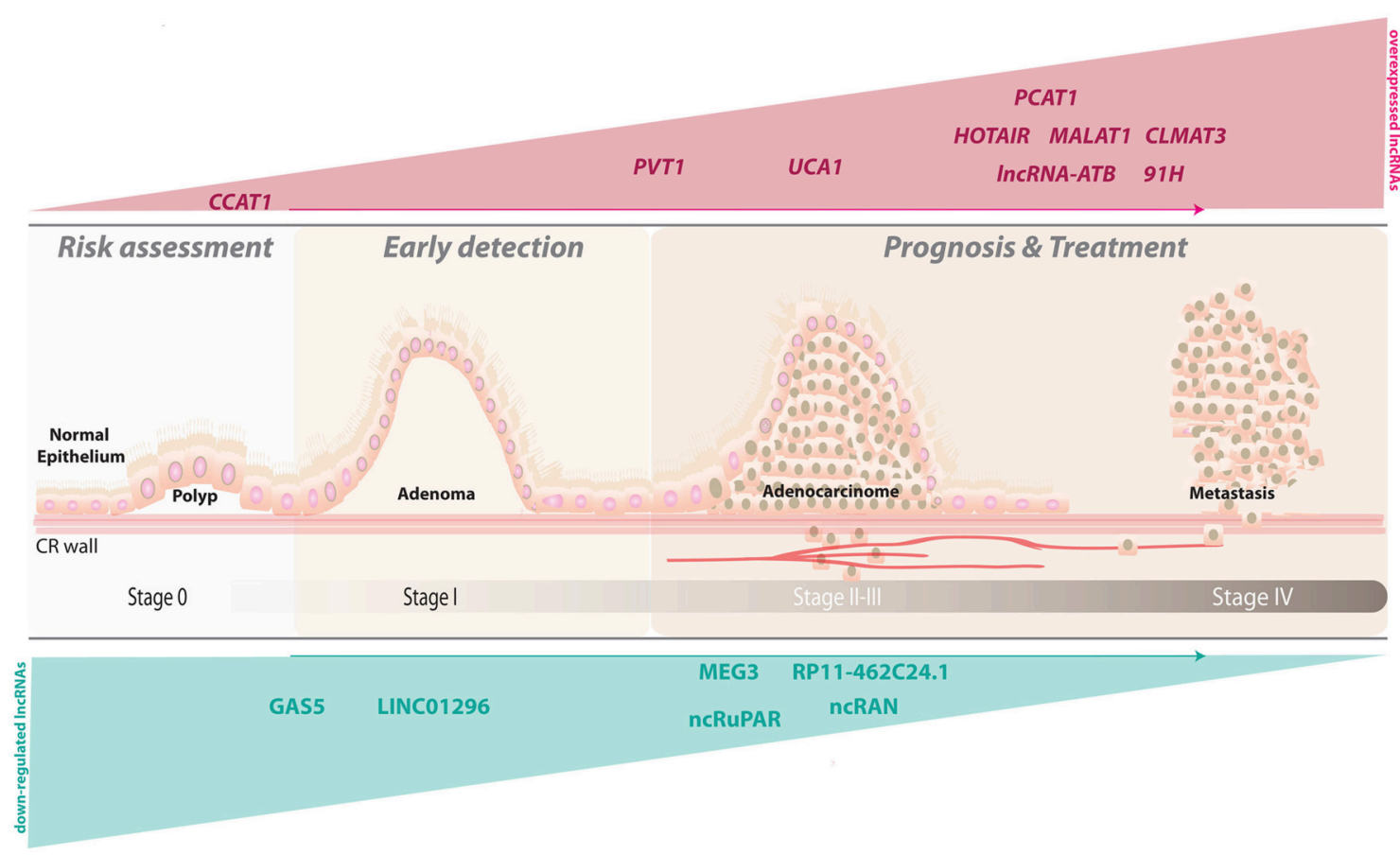

FIGURE 1 | LncRNAs as potential prognostic biomarkers for human colorectal cancer. A depiction of a sagittal view of the colorectal wall showing the progression of lesions associated with CRC and the accompanying alterations in the observed expression levels for several IncRNAs.

However, further studies are needed to elucidate the mechanisms of action of lncRNA DANCR in colorectal cancer.

\section{FEZF1-AS1}

FEZ family zinc finger 1 antisense RNA 1 (FEZF1-AS1) is a recently identified lncRNA which is located in chr7q31.32 on the opposite strand of gene FEZF1. Although its function in normal or cancer cells is still unknown, Chen et al. (2016) have recently identified significantly higher FEZF1-AS1 expression levels in tumor tissues of CRC patients compared to adjacent non-neoplastic mucosa tissues $(P=0.004)$. Specifically, in patients diagnosed with lymph node metastases, the relative mean expression of FEZF1-AS1 was over 2.30 fold higher than in patients without metastases, indicating that FEZF1-AS1 might have a fundamental role in CRC metastasis. Moreover, the authors reported that the up-regulation of lncRNA FEZF1-AS1 was significantly associated with aggressive phenotypes of CRC and poor prognosis in patients with CRC when using KaplanMeier analysis. High expression levels of FEZF1-AS1 in CRC were significantly correlated with overall survival $(P=0.002)$ and disease-free survival ( $P=0.002)$ of CRC patients, with high levels of FEZF1-AS1 being associated with short survival times. Further univariate and multivariate analyses indicated that highlevel expression of FEZF1-AS1 was an independent prognostic factor of outcomes in patients with CRC (HR $=2.401, P=$ 0.035). In a further step, the authors showed that FEZF1-AS1 increases cell proliferation, migration and invasiveness by means of in vitro studies in a panel of CRC cell lines. In addition, FEZF1-AS1 down-regulation in vivo inhibited tumor growth and metastasis, pointing to a promotional role of FEZF1-AS1 in CRC tumorigenesis and progression. Thus, all the results together suggest lncRNA FEZF1-AS1 as a putative prognostic biomarker and a target for new therapies of CRC (Chen et al., 2016).

\section{FTX}

The FTX transcript is a conserved functional lncRNA encoded within the $\mathrm{X}$-inactivation center (XIC). This gene located in chrXq13.2 harbors 4 miRNAs in its introns, the miR-374b/421 cluster and the miR-545/374a cluster. Guo X. B. et al. (2015) measured lncRNA FTX expression in more than 100 CRC samples and found that lncRNA FTX was significantly upregulated in CRC tissues compared with adjacent normal tissues. High lncRNA FTX expression correlated with differentiation grade, lymph vascular invasion and clinical stage. However, there were no significant correlations with other clinicopathological features, such as age, sex, tumor histology, perineural invasion, tumor site, and lymph node metastasis. Multivariate regression analysis indicated that the status of lncRNA FTX expression was an independent predictor of overall survival, as well as differentiation grade and clinical stage, indicating that lncRNA FTX may be a promising prognostic biomarker for CRC patients.

\section{HOTAIR}

HOX Transcript Antisense Intergenic RNA (HOTAIR) is a $2.2 \mathrm{~kb}$ long non-coding RNA transcribed from the antisense strand of HOXC gene cluster, which is located in chromosome 12q13, and which takes part in the epigenetic regulation of gene expression (Gupta et al., 2010). Several studies have shown that HOTAIR is 
TABLE 2 | Compilation of studies showing significant associations between the expression of IncRNAs with CRC clinicopathological features.

\begin{tabular}{|c|c|c|c|c|c|c|c|}
\hline LncRNA & $\begin{array}{l}\text { Study } \\
\text { Design }\end{array}$ & $\begin{array}{c}\text { Sample size } \\
\text { (cohort/validation) }\end{array}$ & $\begin{array}{l}\text { Detection } \\
\text { method }\end{array}$ & $\begin{array}{l}\text { IncRNA expression } \\
\text { in CRC }\end{array}$ & $\begin{array}{l}\text { Clinicopathological } \\
\text { features associated to } \\
\text { CRC }\end{array}$ & $\begin{array}{l}\text { Overall survival } \\
\text { rate }\end{array}$ & References \\
\hline \multicolumn{8}{|c|}{ ONCOGENIC IncRNA } \\
\hline $91 H$ & Cohort & 72 & qRT-PCR ${ }^{1}$ & up-regulated & Poor prognosis, DM & $\begin{array}{l}\mathrm{HR}=3.66 \\
P=0.001\end{array}$ & Deng et al., 2014 \\
\hline CCAT1 & Cohort & 113 & qRT-PCR, ISH & up-regulated & Progression, LNM, LM & ND & Alaiyan et al., 2013 \\
\hline CCAT1 & Cohort & 48 & qRT-PCR ${ }^{1}$ & up-regulated & TNM stage, LNM, poor OS & $\begin{array}{l}\text { Kaplan-Meier } \\
P<0.001\end{array}$ & He et al., 2014 \\
\hline CLMAT3 & Cohort & $30 / 90$ & qRT-PCR ${ }^{1}$ & up-regulated & LM, poor OS & $\mathrm{HR}=2.05, P=0.02$ & Ye et al., 2015 \\
\hline DANCR & Cohort & 104 & qRT-PCR ${ }^{1}$ & up-regulated & TNM stage, LNM & $\begin{array}{l}\mathrm{HR}=2.131 \\
P=0.009\end{array}$ & Liu et al., 2015 \\
\hline FEZF1-AS1 & Cohort & 34 pairs / 153 & qRT-PCR, ISH & up-regulated & TNM stage, LNM, DM & $\begin{array}{l}\mathrm{HR}=2.401 \\
P=0.035\end{array}$ & Chen et al., 2016 \\
\hline FTX & Cohort & 35 pairs / 187 & qRT-PCR & up-regulated & TNM stage, LI, VI & $\begin{array}{l}\mathrm{HR}=2.37 \\
P=0.00041\end{array}$ & $\begin{array}{l}\text { Guo X. B. et al., } \\
2015\end{array}$ \\
\hline HOTAIR & Cohort & $100 / 320$ & qRT-PCR ${ }^{2}$, EA & up-regulated & LM, poor prognosis & $\begin{array}{l}\mathrm{HR}=5.62 \\
P=0.008\end{array}$ & Kogo et al., 2011 \\
\hline HOTAIR & Cohort & 152 & qRT-PCR ${ }^{1}$ & up-regulated & LNM & $\begin{array}{l}\mathrm{HR}=3.915 \\
P=0.021\end{array}$ & Wu Z. H. et al., 2014 \\
\hline HOTAIR & $\begin{array}{l}\text { Meta- } \\
\text { analysis }\end{array}$ & 2,033 & qRT-PCR, EM & up-regulated & Poor prognosis & $\begin{array}{l}{ }^{*} \mathrm{HR}=2.26(95 \% \mathrm{Cl}: \\
1.62-3.15)\end{array}$ & Zhang S. et al., 2014 \\
\hline HOTTIP & Cohort & $156 / 21$ & qRT-PCR ${ }^{1}$ & up-regulated & TNM stage, DM & $\begin{array}{l}H R=2.151 \\
P=0.017\end{array}$ & Ren et al., 2015 \\
\hline IncRNA-ATB & Cohort & 124 & qRT-PCR ${ }^{2}$ & up-regulated & TS, IC, LI, VI, LNM & $\begin{array}{l}\text { Kaplan-Meier } \\
P=0.036\end{array}$ & Iguchi et al., 2015 \\
\hline MALAT1 & Cohort & 147 & qRT-PCR ${ }^{2}$ & up-regulated & Poor prognosis & $\begin{array}{l}\mathrm{HR}=3.968 \\
P=0.002\end{array}$ & Zheng et al., 2014 \\
\hline MALAT1 & $\begin{array}{l}\text { Meta- } \\
\text { analysis }\end{array}$ & 1033 & qRT-PCR, ISH & up-regulated & Poor OS, LNM, DM & $\mathrm{HR}=2.05, P=0.01$ & Wu et al., 2015 \\
\hline PCAT-1 & Cohort & 108 & qRT-PCR ${ }^{1}$ & up-regulated & Poor prognosis and DM & $\mathrm{HR}=3.12, P=0.007$ & Ge et al., 2013 \\
\hline$P V T-1$ & Cohort & 164 & qRT-PCR ${ }^{2}$ & up-regulated & Poor prognosis & $\begin{array}{l}\mathrm{HR}=2.532 \\
P=0.016\end{array}$ & $\begin{array}{l}\text { Takahashi et al., } \\
2014\end{array}$ \\
\hline TUG1 & Cohort & 120 & qRT-PCR & up-regulated & - & $\begin{array}{l}\text { Kaplan-Meier } \\
P<0.001\end{array}$ & Sun et al., 2016 \\
\hline UCA1 & Cohort & 80 & qRT-PCR ${ }^{1}$ & up-regulated & Poor prognosis & $\begin{array}{l}\text { Kaplan-Meier } \\
P=0.046\end{array}$ & Han et al., 2014 \\
\hline UCA1 & Cohort & 54 & qRT-PCR ${ }^{1}$ & up-regulated & $\begin{array}{l}\text { Poor prognosis, LM, DM, } \\
\text { TNM }\end{array}$ & $\begin{array}{l}\mathrm{HR}=3.13 \\
P=0.023\end{array}$ & Ni et al., 2015 \\
\hline \multicolumn{8}{|c|}{ TUMOR SUPPRESSIVE IncRNA } \\
\hline GAS5 & Cohort & 66 & qRT-PCR ${ }^{1}$ & down-regulation & Poor OS & $\begin{array}{l}H R=0.036 \\
P=0.034\end{array}$ & Yin et al., 2014 \\
\hline LINC01296 & $\begin{array}{l}\text { Meta- } \\
\text { analysis }\end{array}$ & $160 / 541$ & EA & down-regulation & - & $\begin{array}{l}H R=0.43 \\
P=0.001\end{array}$ & Qiu and Yan, 2015 \\
\hline MEG3 & Cohort & 62 & qRT-PCR ${ }^{1}$ & down-regulation & TNM stage, tumor invasion & $\begin{array}{l}\mathrm{HR}=0.133 \\
P=0.049\end{array}$ & Yin et al., 2015 \\
\hline$n c R A N^{\star *}$ & Cohort & 80 & qRT-PCR ${ }^{1}$ & down-regulation & - & $\begin{array}{l}{ }^{*} \mathrm{HR}=3.872 \\
P=0.024\end{array}$ & Qi et al., 2015 \\
\hline$n c R u P A R$ & Cohort & 105 & qRT-PCR & down-regulation & - & ND & Yan et al., 2014 \\
\hline$R P 11-462 C 24.1$ & Cohort & 86 & qRT-PCR ${ }^{1}$ & down-regulation & Poor prognosis and DM & $\begin{array}{l}\mathrm{HR}=0.056 \\
P<0.005\end{array}$ & Shi et al., 2014 \\
\hline TUSC7 & Cohort & 81 & qRT-PCR ${ }^{1}$ & down-regulation & TS, TNM stage, DM & $\begin{array}{l}\mathrm{HR}=3.201 \\
P=0.019\end{array}$ & Qi et al., 2013 \\
\hline
\end{tabular}

Abbreviations: ISH, In-situ hybridization; EM, expression microarray; EA, Exon array; qRT-PCR, quantitative real-time PCR using SYBR Green (1) or probe-based detection (2); TNM,

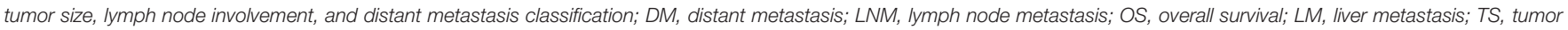
size; IC, colorectal wall invasion; LI, Iymphatic invasion; VI, vascular invasion; HR, hazardous risk; P, p-value; 95\%Cl, 95\% confidence interval; ND, not determined. *Pooled data from a meta-analysis.

**The analysis was carried out considering only ncRAN transcript Nbla10727. 
dysregulated in many cancers, including colorectal carcinomas (Gutschner and Diederichs, 2012; Wu Y. et al., 2014; Hajjari and Salavaty, 2015). Kogo et al. (2011) measured HOTAIR expression in 100 colon cancer tissue samples along with their matched normal tissues and reported significant differences between them. In addition, they detected a strong association between high HOTAIR expression and liver metastasis and poor patient prognosis. Moreover, cDNA microarrays from a specific subgroup of CRC samples obtained by laser microdissection suggested that HOTAIR expression induced genomewide re-targeting of the regulator Polycomb Repressive Complex 2 (PRC2). Furthermore, in vitro studies confirmed invasion promotion by HOTAIR over-expression (Kogo et al., 2011). All these studies suggest that changes in HOTAIR expression may impact the expression of multiple genes by the loss of cooperation with $P R C 2$ complex, resulting in an increase of undifferentiated cancer cells. Thus, HOTAIR is a valuable factor for colorectal cancer prognosis. Moreover, HOTAIR can promote colorectal cancer cell migration and invasiveness and may participate in epithelial-mesenchymal transition. Further studies are warranted to advance our understanding of the involvement of HOTAIR in cancer development, since this lncRNA is a potential target for cancer prevention and treatment (Wu Z. H. et al., 2014). A total of 19 papers comprising 2033 patients were included into this meta-analysis. The authors found that HOTAIR expression was associated with a poorer prognosis in patients with different types of cancer, as well as advanced pathological stage (Zhang S. et al., 2014). Finally, Zhao et al. (2015) have recently found levels of HOTAIR significantly higher in plasma of CRC patients than that of the healthy controls. In the same study, the authors also reported that plasma levels of HOTAIR were significantly decreased in CRC patients after surgical treatment as compared to pre-operative patients, confirming, all together, the potential use of HOTAIR as a diagnostic biomarker for CRC.

\section{HOTTIP}

HOXA transcript at the distal tip (HOTTIP) is a $\sim 3.8 \mathrm{~kb} \operatorname{lncRNA}$, which is spliced and polyadenylated. This gene is located at $5^{\prime}$ end of HOXA cluster and regulates the transcription of HOXA genes in vivo, which are collinearly expressed along the anteroposterior axis (Wang et al., 2011). The coordinated expression of HOTTIP and the adjacent HOXA genes has been observed in normal cells, tumors and also cancer cell lines (Sasaki et al., 2007). HOTTIP is expressed at low levels ( $\sim 0.3$ copies/cell) in several human tissues (colon, prostate, placenta, and uterus) and its expression pattern seems to be conserved from development to adulthood (Sasaki et al., 2007; Wang et al., 2011). A recent study based on $156 \mathrm{CRC}$ and 21 adjacent non-malignant tissues showed that HOTTIP is expressed at significantly higher levels in CRC than normal tissues (Ren et al., 2015). Interestingly, its expression is correlated positively and significantly with $\mathrm{T}$ stage, clinical stage and distant metastasis. Finally, the same authors indicate that the increased expression of HOTTIP may be used as an unfavorable prognosis predictor for CRC patients. A more recent study confirmed that HOTTIP is involved in CRC (Lian et al., 2015). The authors observed that the over-expression of HOTTIP is correlated with advanced pathological stage and larger tumor size. Interestingly, the knockdown of HOTTIP in vivo inhibited the growth of the tumor, suggesting that HOTTIP may be a good candidate for therapy of CRC.

\section{LncRNA-ATB}

A recent exploratory analysis performed in hepatocellular carcinoma cell lines identified a new lncRNA altered upon TGF- $\beta$ activation, named lncRNA-activated by TGF- $\beta$ ( $\operatorname{lncRNA-}$ $A T B)$, that promotes invasion and metastasis through epithelialmesenchymal transition (Yuan et al., 2014). Characterization analyses found that $\operatorname{lncRNA-ATB}$ is $2446 \mathrm{bp}$ long and a BLAST search of the sequence against the human genome showed the presence of three highly homologous regions mapping on chromosomes 13,14 , and 22 . To further elucidate the functional role of $\ln C R N A-A T B$ in CRC, and its implication in invasion and metastasis, a retrospective study used RT-qPCR to determine the expression levels of $\ln c R N A-A T B$ in a CRC tissue dataset. The authors found that $\ln c R N A-A T B$ expression was significantly associated with tumor size, depth, lymphatic invasion, vascular invasion, and lymph node metastasis. Therefore, $\operatorname{lncRNA-ATB}$ may be involved in the progression of CRC and may be a prospective biomarker for invasion and metastasis in CRC. Although this result needs further validation in a larger cohort, $\ln C R N A-A T B$ could represent a molecular target for controlling invasion-metastasis cascade in CRC (Iguchi et al., 2015).

\section{MALAT1}

Metastasis Associated Lung Adenocarcinoma Transcript 1 (MALAT1) is one of the most promising lncRNA in CRC prognosis. It is an $8.75 \mathrm{~kb}$ long non-coding RNA transcribed from the nuclear enriched transcript-2 (NEAT-2) gene, located in chromosome 11q13. Initially associated to non-small cell lung cancer metastasis, the over-expression of MALAT1 has been further described in metastasis of various tumors as hepatocellular carcinoma and endometrial stromal sarcoma (Ji et al., 2003; Smolle et al., 2014). Initial in vitro studies performed in CRC cell lines reported alterations in two fragments of the lncRNA transcript. First, the over-expression of fragment 6918$8441 \mathrm{nt}$ that leads to proliferation and invasion promotion in CRC cells lines. Second, a deletion of 5434-6951 nt fragment that includes a key factor for normal cell functioning, and whose absence contributes to carcinogenic processes (Xu et al., 2011). Next, Yang et al. (2015) confirmed that MALAT1 expression was higher in human CRC cell lines derived from metastasis compared to cells derived from primary CRC tissue. Moreover, over-expression of the activated transcript in SW480 cells promoted cell colony formation, migration and invasion mediated by PRKA (kinase anchor protein 9). The authors also reported that MALAT1 expression was significantly higher in tumors than in their matching normal tissues especially in CRC tissues with lymph node metastasis (Yang et al., 2015). In this regard, another study carried out using RT-qPCR and human CRC tissues (stage II/III) confirmed that MALAT1 expression was 2.26 times higher $(P=0.0004)$ in tumor vs. non-cancerous tissue (Zheng et al., 2014). Besides, association analyses of $M A L A T 1$ expression and patient's prognostic factors such as disease free survival and overall survival indicated that MALAT1 
over-expression is correlated with poor prognosis in CRC patients, whereas multi-variate analysis confirmed MALAT1 as an independent prognostic risk factor. Recently, a meta-analysis including 1216 participants reported a correlation between high MALAT1 expression and three markers of cancer progression: lymph node metastasis, distant metastasis and survival rate $\mathrm{Wu}$ et al., 2015). Overall, these data point to MALAT1 as a potential independent marker of cancer metastasis and prognosis and as a potential molecular target to control cancer metastasis.

\section{PCAT-1}

Prostate cancer-associated ncRNA transcript 1 (PCAT-1) is a long intergenic non-coding RNA codified by a gene located in a gene desert of chromosome $8 \mathrm{q} 24$, about $725 \mathrm{~kb}$ from the $c$-MYC oncogene. PCAT-1 was discovered in 2011 by RNA-sequencing and is implicated in prostate cancer progression (Prensner et al., 2011). PCAT-1 is up-regulated in prostate cancer tumor tissues and it has been shown to promote cell proliferation through association with polycomb repressive complex 2 (PCR2) as a transcriptional repressor. Moreover, down-regulation of PCAT1 by interference RNA was enough to reduce cell proliferation in vitro, pointing to PCAT-1 as a potential therapeutic target of prostate cancer (Prensner et al., 2014). So far, PCAT-1 expression has been associated to few cancer types such as CRC, and esophageal squamous carcinoma (Shi et al., 2015). Ge et al. (2013) explored the potential use of PCAT-1 as a biomarker for CRC diagnosis and therapy. For this, they analyzed the expression levels of PCAT-1 by Real Time qPCR in 108 CRC tumors and 81 matched controls (selected from 2003 to 2007), and observed that PCAT-1 was frequently up-regulated in CRC tissues compared with normal adjacent tissue, and that PCAT-1 was able to stratify overall survival and correlated with distant metastasis in CRC patients. In addition, the over-expression was unrelated to an increment of PCAT-1 gene copy number variants. Multivariate analysis confirmed that PCAT-1 was an independent prognostic factor (Ge et al., 2013). Therefore, PCAT1 may be considered as a novel prognostic biomarker. Since CRC prognosis may be influenced by PCAT-1, the authors suggested that, once elucidated, the molecular mechanisms by which PCAT1 is involved in CRC progression may be useful as an adjuvant therapy target.

\section{PVT1}

The human PVT1 oncogene (non-protein coding) is located at $8 \mathrm{q} 24$. A wide variety of solid tumors carry amplification of the 8q24 locus. Gain of supernumerary copies of the 8q24 chromosomal region has been shown to be common in many human cancers and is associated with poor prognosis. Overexpression of $P V T 1$ has been suggested as a powerful predictor of tumor progression and patient survival in a diverse range of cancer types, such as pancreatic cancer (Huang et al., 2015), gastric cancer (Kong et al., 2015), hepatocellular cancer (Ding et al., 2015), ovarian and breast cancer (Guan et al., 2007). Another remarkable feature of the PVT1 locus is that it resides about $60 \mathrm{~kb}$ apart from the 3-prime of the well-known MYC oncogene and that these two genes are co-amplified in CRC cell lines (Shtivelman and Bishop, 1989; Tseng et al., 2014).
Takahashi et al. (2014) showed that PVT1 expression levels in colorectal cancer tissues were significantly higher than those in non-cancerous tissues. Knockdown of PVT1 significantly inhibited colorectal cancer cells proliferation and reduced invasive abilities compared with negative control cells. Moreover, down-regulated PVT1 promotes colorectal cancer cells apoptosis. The authors found that colorectal cancer patients with high PVT1 expression had a significantly poorer prognosis than those with low PVT1 expression $(P=0.0101)$. Univariate and multivariate analyses showed that PVT1 expression level was an independent prognostic indicator of overall survival in patients with CRC (relative risk: $2.532 P=0.016$; Takahashi et al., 2014).

\section{TUG1}

Taurine up-regulated gene 1 (TUG1) is a $9.7 \mathrm{~kb}$ gene mapping to chromosome $22 \mathrm{q} 12$ that codifies a long non-coding RNA. TUG1 is highly conserved in mammals, and was originally detected in a genomic screen in taurine treated mouse retinal cells (Young et al., 2005). In this study, the authors found that TUG1 knockdown resulted in malformed or non-existent outer segments of transfected photoreceptors through increased apoptosis in the newborn retina. In humans, elevated levels of TUG1 have been found in the caudate nucleus of patients suffering from Huntington's disease (Johnson, 2012), whereas additional studies showed that lncRNA TUG1 was involved in cancer progression, affecting apoptosis and proliferation in several human tumor cells. Zhang et al. (2013) proved that lncRNA TUG1 is generally up-regulated in osteosarcoma and regulates proliferation and apoptosis of osteosarcoma cells. Han et al. (2013) reported that high TUG1 expression levels were associated with high grade and stage of urothelial carcinoma of the bladder, whereas its silencing led to cell proliferation inhibition and apoptosis induction. Recently, another study (Sun et al., 2016) suggested that TUG1 could play a critical role in CRC metastasis, and that it may serve both as a prognostic biomarker and therapeutic target. After analyzing the expression levels of TUG1 in 120 CRC patients, the authors observed an up-regulation of the IncRNA in tumor tissue that in addition was closely correlated with the survival time of the CRC patients. Further in vitro analyses showed the oncogenic effect of TUG1 over-expression in CRC cell lines. TUG1 over-expression increased colony formation, migration and metastatic potential in vivo. Besides, the authors showed that TUG1 activated EMTrelated gene expression.

\section{UCA1}

Urothelial Cancer Associated 1 (UCA1) is a lncRNA originally identified in bladder transitional cell carcinoma (Wang et al., 2006). The sequence of $7.37 \mathrm{~kb}$ is located in $19 \mathrm{p} 13$ chromosome. The proliferative, migratory, invasive, and drug resistance behaviors of human bladder TCC cell line BLS-211 were enhanced by exogenous UCA1 expression in vitro (Wang et al., 2006). UCA1 has been found significantly up-regulated in most tumors and cancer cells, including colorectal cancer. A multivariate survival analysis also indicated that UCA1 could be an independent prognostic marker in gastric cancer. Han and collaborators found that UCA1 levels were markedly 
increased in colorectal cancer tissues and cells, and that they influenced proliferation, apoptosis and cell cycle progression of colorectal cancer cells (Han et al., 2014). In addition, the authors assessed the correlation between UCA1 expression and various clinicopathological data. They demonstrated that patients with high UCA1 expression levels had a larger tumor size, less differentiated histology and greater tumor depth as compared to the low UCA1 expression group. Furthermore, patients with high UCA1 expression had a significantly poorer prognosis compared to patients with low UCA1 expression $(P=0.046)$. Recently, $\mathrm{Ni}$ and colleagues reported that the expression of UCA1 was statistically correlated with lymph node metastasis, distant metastasis and tumor stage. Finally, patients with high UCA1 expression had a poor prognosis and multivariate analysis indicated that UCA1 over-expression is an independent predictor for CRC (Ni et al., 2015).

\section{TUMOR SUPPRESSIVE LncRNAs ASSOCIATED WITH PROGNOSIS IN COLORECTAL CANCER}

\section{GAS5}

First described as a tumor suppressor in 1988, the Growth Arrest-Specific transcript 5 (GAS5) is a $630 \mathrm{nt}$ long non-coding transcript transcribed by a gene located in chromosome 1q25 (Schneider et al., 1988). Previous studies showed that GAS5 was able to bind the glucocorticoid receptor (GR) in growth arrested cells, influencing cell survival, metabolic regulation (Kino et al., 2010), and apoptosis (Mourtada-Maarabouni et al., 2008) when over-expressed. Conversely, GAS5 down-regulation has been related to different types of cancer such as breast (MourtadaMaarabouni et al., 2009), prostate (Pickard et al., 2013), renal cancer (Qiao et al., 2013), and more recently to cervical (Cao et al., 2014), and gastric cancer (Guo X. et al., 2015). Regarding CRC, Yin et al. (2014) observed that GAS5 is down-regulated in human CRC tissues compared to the adjacent normal lung tissues, and that lower levels of GAS5 are correlated with larger tumor size, low histological grade and advanced TNM stage, consistent with previous observations. Furthermore, the analysis of GAS5 expression and prognosis showed that patients with low levels of GAS5 had remarkably shorter survival time than those with high levels $(P<0.001)$. Multivariate analysis revealed that GAS5 expression was a significant independent predictor of poor survival of CRC patients $(P=0.034)$, suggesting an important role of GAS5 in CRC development and progression. In order to confirm these results, the authors tested the effect of GAS5 over-expression both in vitro (HCT-116 and DLD-1) and in vivo (CRC xenografts mice) and observed that over-expression of GAS5 could inhibit cell proliferation (Yin et al., 2014).

\section{LINC01296}

LINC01296 was identified by Qiu and Yan (2015) after reanalyzing five Affymetrix Human Exon 1.0 ST published datasets from Gene Expression Omnibus (GEO). In total 355 samples were chosen to identify differentially expressed lncRNAs and their potential as diagnostic biomarkers for CRC. Twenty-five
lncRNAs were differentially expressed between CRC tissue and tumor-adjacent normal tissue samples. Among them, LINC01296 was shown to be significantly associated with the overall survival of patients with CRC. Univariate and multivariate analysis between expression levels of LINC01296 and TNM stages as well as MSI (microsatellite instability) status indicated that LINC01296 was a significant predictor of survival in CRC $(P=$ $0.001)$ in addition to TNM stage $(P=0.001)$ and MSI status $(P=0.006)$. These results were validated in an independent series suggesting that LINC01296 could be a novel prognostic biomarker for CRC (Qiu and Yan, 2015).

\section{MEG3}

Maternally Expressed Gene 3 (MEG3) gene is located in chromosome $14 \mathrm{q} 32$, encodes a lncRNA and belongs to the imprinted DLK1-MEG3 locus which contains some maternally and paternally imprinted genes (Benetatos et al., 2011). It is expressed in many normal tissues but multiple mechanisms contribute to the loss of MEG3 expression in tumors, including gene dosage and epigenetic changes. Strong evidence exists to support that MEG3 is a lncRNA tumor suppressor (Zhou et al., 2012). Yin et al. (2015) found that MEG3 expression is downregulated in CRC tumor tissue and that may regulate CRC cell proliferation in vitro and in vivo. They also demonstrated that $M E G 3$ levels were remarkably correlated with histological grade, deeper tumor invasion, and advanced TNM stage $(P<0.001)$. Univariate and multivariate analyses show MEG3 expression as an independent predictor for overall survival (Yin et al., 2015).

\section{ncRAN}

Non-coding RNA expressed in Aggressive Neuroblastoma $(n c R A N)$ is a long non-coding transcript mapping to chromosome 17q25, a region of frequent gains in neuroblastoma that harbors two transcripts (Nbla10727, Nbla12061). Initially, it has been reported that high levels of $n c R A N$ lncRNA were significantly associated with poor neuroblastoma patient's outcome (Yu et al., 2009), as well as enhanced cell proliferation, migration and invasion in bladder cancer cell lines (Zhu et al., 2011). Conversely, recent studies performed in CRC reported down-regulation of $n c R A N$ in CRC fresh tumors and cell lines compared with normal adjacent tissue and normal intestinal mucosa cell line. Besides, reduced expression of ncRAN was associated with poorly differentiated tumors, liver metastasis and reduced overall survival rate. In vitro studies showed that $n c R A N$ may mediate cell invasion and migration of CRC cells with little or no effect in cell proliferation, thus pointing to $n c R A N$ as a new potential early diagnostic biomarker (Smolle et al., 2014; Qi et al., 2015). Overall, there is strong evidence that the expression pattern of $n c R N A$ is tumor-dependent.

\section{ncRuPAR}

$n c R u P A R$ is a newly discovered long noncoding RNA molecule, located in $5 \mathrm{q} 13$ chromosome, that can up-regulate proteaseactivated receptor-1 (PAR-1) during embryonic growth. PAR-1 has been implicated in tumor growth, invasion, and metastasis in several malignancies including colonic adenocarcinoma (Dorsam 
and Gutkind, 2007; Adams et al., 2015). Up-regulation of PAR1 expression has been found in gastric cancer (Liu et al., 2014), invasive breast cancer, colon cancer (Darmoul et al., 2003), and advanced stage prostate cancer (Wang et al., 2014). Adams et al. (2015) established a functional role for thrombin and its targets PAR-1 and fibrinogen in the pathogenesis of colonic adenocarcinoma, supporting tumor growth as well as local invasion and metastasis (Adams et al., 2015). Recently, the study of Yan et al. (2014) found that $n c R u P A R$ expression in CRC tissues was statistically lower than in adjacent normal tissue. Moreover, the authors reported that expression of $n c R u P A R$ was significantly correlated with lymph node metastasis, distant metastasis, Dukes' stage (Haq et al., 2009), differentiation, and TNM stage (Yan et al., 2014). These findings suggest that $n c R u P A R$ could act as a biomarker for progression and prognosis of CRC.

\section{RP11-462C24.1}

RP11-462C24.1 is a long non-coding RNA consisting of four exons with a length of $1136 \mathrm{bp}$, located in chromosome 4q25 and with an unknown function. A prospective analysis screened the aberrant expression of lncRNAs comparing CRC tumor tissues and normal adjacent tissues, as well as CRC metastatic tumors and non-metastatic tumors (Shi et al., 2014). Six lncRNAs were selected for RT-qPCR validation in an independent cohort of 86 CRC patients, based on their genomic location and expression levels. Then, the authors explored the association of RP11-462C24.1 expression with clinicopathological factors. The analysis showed a decreased expression of the lncRNA RP11462C24.1 in tumor tissues compared with normal adjacent tissue $(P<0.001)$. Moreover, RP11-462C24.1 expression was also lower in CRC patients with metastasis than those without metastasis $(P<0.049)$, and its low expression significantly correlated with more distant metastasis $(P<0.011)$. Multivariate analysis identified $R P 11-462 C 24.1$ as an independent prognostic factor for CRC $(P<0.005)$, whereas Kaplan-Meier analysis showed that patients with low expression of RP11-462C24.1 had a poor disease-free survival $(P<0.001)$. Overall, $R P 11-462 C 24.1$ could be considered a potential prognostic biomarker, providing a new strategy for diagnosis. The study also implicates RP11-462C24.1 in the tumorigenesis and progression of CRC, and identifies it as a potential target for further therapeutic studies (Shi et al., 2014).

\section{TUSC7}

TUSC7, also known as LOC285194, is a lncRNA of 2105 nt in length located in chr3q13.31. It was first reported in osteosarcoma samples and cell lines, where depletion of TUSC7 promoted proliferation of normal osteoblasts by regulation of apoptotic genes and cell cycle transcripts. Recent studies showed a potential tumor-suppressor role of this lncRNA in several cancers such as esophageal squamous cell carcinoma (Tong et al., 2014), pancreatic ductal adenocarcinoma (Ding et al., 2014) and colorectal cancer (Qi et al., 2013). Liu et al. (2013) showed that TUSC7 is a direct transcription target of p53, and that ectopic expression of TUSC7 inhibits tumor cell growth both in vitro and in vivo. Moreover, the authors determined the expression of
TUSC7 in colon cancer tissue by microarrays and showed that TUSC7 was down-regulated in tumor specimens compared with normal specimens. Finally, Qi et al. (2013) demonstrated that relative expression levels of TUSC7 were lower in a cohort of 81 tumor tissues from CRC patients and CRC cell lines compared to adjacent normal tissues and normal intestinal mucous cell line. The authors also assessed the correlation between TUSC7 expression and clinicopathological data in CRC patients, and found that low expression of TUSC7 was correlated with larger tumor size, higher tumor stage, and more distant metastasis. In addition, Kaplan-Meier analysis showed that patients with low TUSC7 expression had a significantly poorer prognosis than those with high TUSC7 expression $(P=0.010)$. All these data indicate that this IncRNA could represent a good candidate to consider as a potential biomarker for CRC prognosis and development.

\section{CONCLUSIONS AND FUTURE PERSPECTIVES}

Colorectal cancer is one of the most commonly diagnosed cancers worldwide, and approximately half of all CRC patients die from distant metastasis. Thus, the key to improve CRC patients' survival is early diagnosis and early prediction of future metastasis. Diagnosis and prognosis markers are required to select the best-suited treatment under preoperative or postoperative conditions.

Advances in lncRNA expression profiling in human cancer have highlighted their potential value as tumor biomarkers in patient diagnosis and prognosis. Previous studies showed that lncRNAs play an important role in regulating gene expression at various levels, including chromatin modification, transcription, and post-transcriptional processing. In addition, lncRNAs have been reported to have tumor suppressor and oncogenic roles. In particular, levels of several lncRNAs are correlated with TNM stage, lymph node involvement, distant metastasis and overall survival. This data indicates that lncRNAs could offer clinical applications, both as diagnostic and prognostic markers, but also as novel specific therapeutic targets.

Another advantage of lncRNAs is that they may be used in clinics as minimally-invasive biomarkers due to their presence in body fluids, such as urine and plasma or serum. For example, HOTAIR and MALAT1 have been reported as diagnostic and prognostic markers in the serum/plasma of cancer patients (Svoboda et al., 2014; Kishikawa et al., 2015). In plasma, H19 is differentially expressed in patients with gastric cancer compared to healthy controls (Arita et al., 2013). Future studies on circulating lncRNAs would allow us to identify lncRNAs as putative minimally-invasive biomarkers for CRC. In this regard, a challenging aspect is the low expression levels of some lncRNAs, which brings about the need for using protocols based on amplification and/or enrichment of the circulating molecules.

It is important to bear in mind that, although in this review we have only focused and comprehensively described the lncRNAs significantly associated to CRC prognosis, other lncRNAs previously found dysregulated in CRC patients or 
associated to prognosis in other types of cancer should also be considered in future studies when looking for biomarkers of CRC prognosis. Among them, for example, Colon Cancer Associated Transcript 2 (CCAT2) is overexpressed in microsatellite stable CRC samples (Ling et al., 2013). Although a recent study failed to detect CCAT2 in human CRC tissue or CRC cell lines (Xiang et al., 2014), elevated expression of CCAT2 has been associated with poor prognosis in a wide range of cancers, including breast cancer (Redis et al., 2013), non-small cell lung cancer (Qiu et al., 2014), gastric cancer (Wang C. Y. et al., 2015), and esophageal squamous cell carcinoma (Zhang et al., 2015). Another well-established up-regulated lncRNA associated with CRC and other cancer types is Colorectal Neoplasia Differentially Expressed gene (CRNDE). CRNDE is activated during early steps of CRC development, and its expression is highly elevated in colorectal adenomas and adenocarcinomas (Graham et al., 2011). CRNDE was also reported to promote glioma cell growth and invasion, being highly up-regulated both in patients with glioma and in vitro cell lines (Wang Y. et al., 2015), and a recent study showed evidence of CRNDE as a potential marker of poor prognosis in women with ovarian carcinomas, with different outcomes depending on the therapeutic regimen used (Szafron et al., 2015). In addition, a very recent study (Esposti et al., 2016) confirmed CRNDE as well as lncRNA H19, among other known and new oncogenic lncRNAs, to be up-regulated in patients with hepatocellular carcinoma when performing RNA-Seq analyses in 23 liver tissues (controls, cirrhotic and hepatocellular carcinomas). Indeed, increased levels of the H19 transcript have been observed in many cancers, including CRC (Liang et al., 2015), suggesting that H19 and its gene products may be involved in tumor progression although prognostic value has not been proven so far. Thus, apart from the reviewed lncRNAs clearly linked to CRC prognosis, several studies have identified a large number of other lncRNAs that are dysregulated in CRC (reviewed in Ragusa et al., 2015; Xie et al., 2015). Since they may be potential prognostic biomarkers once their

\section{REFERENCES}

Adams, G. N., Rosenfeldt, L., Frederick, M., Miller, W., Waltz, D., Kombrinck, K., et al. (2015). Colon cancer growth and dissemination relies upon thrombin, stromal PAR-1, and fibrinogen. Cancer Res. 75, 4235-4243. doi: 10.1158/00085472.CAN-15-0964

Alaiyan, B., Ilyayev, N., Stojadinovic, A., Izadjoo, M., Roistacher, M., Pavlov, V., et al. (2013). Differential expression of colon cancer associated transcript1 (CCAT1) along the colonic adenoma-carcinoma sequence. BMC Cancer 13:196. doi: 10.1186/1471-2407-13-196

Aranha, O., and Benson, A. B. III. (2007). Adjuvant therapy for colon cancer. Curr. Gastroenterol. Rep. 9, 415-421. doi: 10.1007/s11894-0070052-x

Arita, T., Ichikawa, D., Konishi, H., Komatsu, S., Shiozaki, A., Shoda, K., et al. (2013). Circulating long non-coding RNAs in plasma of patients with gastric cancer. Anticancer Res. 33, 3185-3193.

Benetatos, L., Vartholomatos, G., and Hatzimichael, E. (2011). MEG3 imprinted gene contribution in tumorigenesis. Int. J. Cancer 129, 773-779. doi: $10.1002 / \mathrm{ijc} .26052$

Benson, A. B., III., Schrag, D., Somerfield, M. R., Cohen, A. M., Figueredo, A. T., Flynn, P. J., et al. (2004). American Society of Clinical Oncology recommendations on adjuvant chemotherapy for stage II colon cancer. J. Clin. Oncol. 22, 3408-3419. doi: 10.1200/JCO.2004.05.063 sensitivities and specificities are established, we think they should be taken into account in future analyses studying the possible role and use of lncRNAs as prognostic biomarkers in CRC.

Taken together, the use of lncRNAs as CRC prognostic biomarkers seems very promising. In the future, further characterization of these lncRNAs and greater understanding of their molecular function may support their clinical use for improving cancer diagnosis, monitoring cancer progression and as targeted therapies.

\section{AUTHOR CONTRIBUTIONS}

$\mathrm{ES}, \mathrm{ABV}$, and SIG authors make substantial contributions to conception, design, and acquisition of data. Participate in drafting the article, tables and the figure. CP, TG, and C. Pericay revised the article critically for important intellectual content and give final approval of the version to be submitted. ES, ABV and SIG authors have equal contributions. TG and C. Pericay share senior authorship and correspondence.

\section{ACKNOWLEDGMENTS}

The authors thank Jesse R. Willis for his help in editing the manuscript. TG group acknowledges support of the Spanish Ministry of Economy and Competitiveness grants, 'Centro de Excelencia Severo Ochoa 2013-2017' SEV-20120208, and BIO2012-37161 cofounded by European Regional Development Fund (ERDF); from the European Union and ERC Seventh Framework Programme (FP7/2007-2013) under grant agreement ERC-2012-StG-310325, and a grant from the European Union's Horizon 2020 research and innovation programme under the Marie Sklodowska-Curie grant agreement No H2020-MSCA-ITN-2014-642095. CP group acknowledges support from the Fundació Parc Taulí by grants CIR2010040 and CIR2014023 (http://www.tauli.cat/tauli/en/ Fpt/fpt.htm).

Berteaux, N., Aptel, N., Cathala, G., Genton, C., Coll, J., Daccache, A., et al. (2008). A novel H19 antisense RNA overexpressed in breast cancer contributes to paternal IGF2 expression. Mol. Cell. Biol. 28, 6731-6745. doi: 10.1128/MCB.02103-07

Burke, H. B. (2004). Outcome prediction and the future of the TNM staging system. J. Natl. Cancer Inst. 96, 1408-1409. doi: 10.1093/jnci/djh293

Calin, G. A., Liu, C. G., Ferracin, M., Hyslop, T., Spizzo, R., Sevignani, C., et al. (2007). Ultraconserved regions encoding ncRNAs are altered in human leukemias and carcinomas. Cancer Cell 12, 215-229. doi: 10.1016/j.ccr.2007.07.027

Cao, S., Liu, W., Li, F., Zhao, W., and Qin, C. (2014). Decreased expression of IncRNA GAS5 predicts a poor prognosis in cervical cancer. Int. J. Clin. Exp. Pathol. 7, 6776-6783.

Chen, N., Guo, D., Xu, Q., Yang, M., Wang, D., Peng, M., et al. (2016). Long non-coding RNA FEZF1-AS1 facilitates cell proliferation and migration in colorectal carcinoma. Oncotarget. doi: 10.18632/oncotarget.7168. [Epub ahead of print].

Consortium, E. P. (2012). An integrated encyclopedia of DNA elements in the human genome. Nature 489, 57-74. doi: 10.1038/nature11247

Darmoul, D., Gratio, V., Devaud, H., Lehy, T., and Laburthe, M. (2003). Aberrant expression and activation of the thrombin receptor protease-activated receptor1 induces cell proliferation and motility in human colon cancer cells. Am. J. Pathol. 162, 1503-1513. doi: 10.1016/S0002-9440(10)64283-6 
Deng, Q., He, B., Gao, T., Pan, Y., Sun, H., Xu, Y., et al. (2014). Up-regulation of $91 \mathrm{H}$ promotes tumor metastasis and predicts poor prognosis for patients with colorectal cancer. PLOS ONE 9:e103022. doi: 10.1371/journal.pone.0103022

Derrien, T., Johnson, R., Bussotti, G., Tanzer, A., Djebali, S., Tilgner, H., et al. (2012). The GENCODE v7 catalog of human long noncoding RNAs: analysis of their gene structure, evolution, and expression. Genome Res. 22, 1775-1789. doi: $10.1101 /$ gr.132159.111

Ding, C., Yang, Z., Lv, Z., Du, C., Xiao, H., Peng, C., et al. (2015). Long non-coding RNA PVT1 is associated with tumor progression and predicts recurrence in hepatocellular carcinoma patients. Oncol. Lett. 9, 955-963. doi: 10.3892/ol.2014.2730

Ding, Y. C., Yu, W., Ma, C., Wang, Q., Huang, C. S., and Huang, T. (2014). Expression of long non-coding RNA LOC285194 and its prognostic significance in human pancreatic ductal adenocarcinoma. Int. J. Clin. Exp. Pathol. 7, 8065-8070.

Dorsam, R. T., and Gutkind, J. S. (2007). G-protein-coupled receptors and cancer. Nat. Rev. Cancer 7, 79-94. doi: 10.1038/nrc2069

Esposti, D. D., Hernandez-Vargas, H., Voegele, C., Fernandez-Jimenez, N., Forey, N., Bancel, B., et al. (2016). Identification of novel long non-coding RNAs deregulated in hepatocellular carcinoma using RNA-sequencing. Oncotarget. doi: 10.18632/oncotarget.7364. [Epub ahead of print].

Ferlay, J., Soerjomataram, I., Dikshit, R., Eser, S., Mathers, C., Rebelo, M., et al. (2015). Cancer incidence and mortality worldwide: sources, methods and major patterns in GLOBOCAN 2012. Int. J. Cancer 136, E359-E386. doi: $10.1002 /$ ijc. 29210

Gao, T., He, B., Pan, Y., Xu, Y., Li, R., Deng, Q., et al. (2015). Long non-coding RNA $91 \mathrm{H}$ contributes to the occurrence and progression of esophageal squamous cell carcinoma by inhibiting IGF2 expression. Mol. Carcinog. 54, 359-367. doi: $10.1002 / \mathrm{mc} .22106$

Ge, X., Chen, Y., Liao, X., Liu, D., Li, F., Ruan, H., et al. (2013). Overexpression of long noncoding RNA PCAT-1 is a novel biomarker of poor prognosis in patients with colorectal cancer. Med. Oncol. 30:588. doi: 10.1007/s12032-0130588-6

Graham, L. D., Pedersen, S. K., Brown, G. S., Ho, T., Kassir, Z., Moynihan, A. T., et al. (2011). Colorectal neoplasia differentially expressed (CRNDE), a novel gene with elevated expression in colorectal adenomas and adenocarcinomas. Genes Cancer 2, 829-840. doi: 10.1177/1947601911431081

Guan, Y., Kuo, W. L., Stilwell, J. L., Takano, H., Lapuk, A. V., Fridlyand, J., et al. (2007). Amplification of PVT1 contributes to the pathophysiology of ovarian and breast cancer. Clin. Cancer Res. 13, 5745-5755. doi: 10.1158/10780432.CCR-06-2882

Guo, X. B., Hua, Z., Li, C., Peng, L. P., Wang, J. S., Wang, B., et al. (2015). Biological significance of long non-coding RNA FTX expression in human colorectal cancer. Int. J. Clin. Exp. Med. 8, 15591-15600.

Guo, X., Deng, K., Wang, H., Xia, J., Shan, T., Liang, Z., et al. (2015). GAS5 Inhibits Gastric Cancer Cell Proliferation Partly by Modulating CDK6. Oncol. Res. Treat. 38, 362-366. doi: 10.1159/000433499

Gupta, R. A., Shah, N., Wang, K. C., Kim, J., Horlings, H. M., Wong, D. J., et al. (2010). Long non-coding RNA HOTAIR reprograms chromatin state to promote cancer metastasis. Nature 464, 1071-1076. doi: 10.1038/nature08975

Gutschner, T., and Diederichs, S. (2012). The hallmarks of cancer: a long noncoding RNA point of view. RNA Biol. 9, 703-719. doi: 10.4161/rna.20481

Haerian, M. S., Baum, L., and Haerian, B. S. (2011). Association of 8q24.21 loci with the risk of colorectal cancer: a systematic review and meta-analysis. J. Gastroenterol. Hepatol. 26, 1475-1484. doi: 10.1111/j.1440-1746.2011.06831.x

Hajjari, M., and Salavaty, A. (2015). HOTAIR: an oncogenic long non-coding RNA in different cancers. Cancer Biol. Med. 12, 1-9. doi: 10.7497/j.issn.20953941.2015.0006

Han, Y., Liu, Y., Gui, Y., and Cai, Z. (2013). Long intergenic non-coding RNA TUG1 is overexpressed in urothelial carcinoma of the bladder. J. Surg. Oncol. 107, 555-559. doi: 10.1002/jso.23264

Han, Y., Yang, Y. N., Yuan, H. H., Zhang, T. T., Sui, H., Wei, X. L., et al. (2014). UCA1, a long non-coding RNA up-regulated in colorectal cancer influences cell proliferation, apoptosis and cell cycle distribution. Pathology 46, 396-401. doi: 10.1097/PAT.0000000000000125

Haq, A. I., Schneeweiss, J., Kalsi, V., and Arya, M. (2009). The Dukes staging system: a cornerstone in the clinical management of colorectal cancer. Lancet Oncol. 10:1128. doi: 10.1016/S1470-2045(09)70157-3
He, X., Tan, X., Wang, X., Jin, H., Liu, L., Ma, L., et al. (2014). C-Myc-activated long noncoding RNA CCAT1 promotes colon cancer cell proliferation and invasion. Tumour Biol. 35, 12181-12188. doi: 10.1007/s13277-014-2526-4

Hu, Y., Chen, H. Y., Yu, C. Y., Xu, J., Wang, J. L., Qian, J., et al. (2014). A long noncoding RNA signature to improve prognosis prediction of colorectal cancer. Oncotarget 5, 2230-2242. doi: 10.18632/oncotarget.1895

Huang, C., Yu, W., Wang, Q., Cui, H., Wang, Y., Zhang, L., et al. (2015). Increased expression of the lncRNA PVT1 is associated with poor prognosis in pancreatic cancer patients. Minerva Med. 106, 143-149.

Iguchi, T., Uchi, R., Nambara, S., Saito, T., Komatsu, H., Hirata, H., et al. (2015). A long noncoding RNA, IncRNA-ATB, is involved in the progression and prognosis of colorectal cancer. Anticancer Res. 35, 1385-1388.

Iyer, M. K., Niknafs, Y. S., Malik, R., Singhal, U., Sahu, A., Hosono, Y., et al. (2015). The landscape of long noncoding RNAs in the human transcriptome. Nat. Genet. 47, 199-208. doi: 10.1038/ng.3192

Jass, J. R. (2006). Colorectal cancer: a multipathway disease. Crit. Rev. Oncog. 12, 273-287. doi: 10.1615/CritRevOncog.v12.i3-4.50

Ji, P., Diederichs, S., Wang, W., Boing, S., Metzger, R., Schneider, et al. (2003). MALAT-1, a novel noncoding RNA, and thymosin beta4 predict metastasis and survival in early-stage non-small cell lung cancer. Oncogene 22, 8031-8041. doi: $10.1038 /$ sj.onc. 1206928

Ji, Q., Liu, X., Fu, X., Zhang, L., Sui, H., Zhou, L., et al. (2013). Resveratrol inhibits invasion and metastasis of colorectal cancer cells via MALAT1 mediated Wnt/ $\beta$-catenin signal pathway. PLoS ONE 8:e78700. doi: 10.1371/journal.pone.0078700

Ji, Q., Zhang, L., Liu, X., Zhou, L., Wang, W., Han, Z., et al. (2014). Long non-coding RNA MALAT1 promotes tumour growth and metastasis in colorectal cancer through binding to SFPQ and releasing oncogene PTBP2 from SFPQ/PTBP2 complex. Br. J. Cancer 111, 736-748. doi: 10.1038/bjc. 2014.383

Jia, Q., Jiang, W., and Ni, L. (2015). Down-regulated non-coding RNA (lncRNAANCR) promotes osteogenic differentiation of periodontal ligament stem cells, Arch. Oral. Biol. 60, 234-241. doi: 10.1016/j.archoralbio.2014.10.007

Johnson, R. (2012). Long non-coding RNAs in Huntington's disease neurodegeneration. Neurobiol. Dis. 46, 245-254. doi: 10.1016/j.nbd.2011.12.006

Johnsson, P., Lipovich, L., Grander, D., and Morris, K. V. (2014). Evolutionary conservation of long non-coding RNAs; sequence, structure, function. Biochim. Biophys. Acta 1840, 1063-1071. doi: 10.1016/j.bbagen.2013.10.035

Kino, T., Hurt, D. E., Ichijo, T., Nader, N., and Chrousos, G. P. (2010). Noncoding RNA gas5 is a growth arrest- and starvation-associated repressor of the glucocorticoid receptor. Sci. Signal 3:ra8. doi: 10.1126/scisignal.2000568

Kishikawa, T., Otsuka, M., Ohno, M., Yoshikawa, T., Takata, A., and Koike, K. (2015). Circulating RNAs as new biomarkers for detecting pancreatic cancer. World J. Gastroenterol. 21, 8527-8540. doi: 10.3748/wjg.v21.i28.8527

Kogo, R., Shimamura, T., Mimori, K., Kawahara, K., Imoto, S., Sudo, T., et al. (2011). Long noncoding RNA HOTAIR regulates polycomb-dependent chromatin modification and is associated with poor prognosis in colorectal cancers. Cancer Res. 71, 6320-6326. doi: 10.1158/0008-5472.CAN-11-1021

Kong, R., Zhang, E. B., Yin, D. D., You, L. H., Xu, T. P., Chen, W. M., et al. (2015). Long noncoding RNA PVT1 indicates a poor prognosis of gastric cancer and promotes cell proliferation through epigenetically regulating p15 and p16. Mol. Cancer 14:82. doi: 10.1186/s12943-015-0355-8

Kretz, M., Webster, D. E., Flockhart, R. J., Lee, C. S., Zehnder, A., LopezPajares, V., et al. (2012). Suppression of progenitor differentiation requires the long noncoding RNA ANCR. Genes Dev. 26, 338-343. doi: 10.1101/gad.1821 21.111

Lian, Y., Ding, J., Zhang, Z., Shi, Y., Zhu, Y., Li, J., et al. (2015). The long noncoding RNA HOXA transcript at the distal tip promotes colorectal cancer growth partially via silencing of p21 expression. Tumor Biol. doi: 10.1007/s13277-0154617-2. [Epub ahead of print].

Liang, W. C., Fu, W. M., Wong, C. W., Wang, Y., Wang, W. M., Hu, G. X., et al. (2015). The lncRNA H19 promotes epithelial to mesenchymal transition by functioning as miRNA sponges in colorectal cancer. Oncotarget 6, 22513-22525. doi: 10.18632/oncotarget.4154

Ling, H., Spizzo, R., Atlasi, Y., Nicoloso, M., Shimizu, M., Redis, R. S., et al. (2013). CCAT2, a novel noncoding RNA mapping to 8q24, underlies metastatic progression and chromosomal instability in colon cancer. Genome Res. 23, 1446-1461. doi: 10.1101/gr.152942.112 
Liu, L., Yan, B., Yang, Z., Zhang, X., Gu, Q., and Yue, X. (2014). ncRuPAR inhibits gastric cancer progression by down-regulating protease-activated receptor-1. Tumour Biol. 35, 7821-7829. doi: 10.1007/s13277-014-2042-6

Liu, Q., Huang, J., Zhou, N., Zhang, Z., Zhang, A., Lu, Z., et al. (2013). LncRNA loc285194 is a p53-regulated tumor suppressor. Nucleic Acids Res. 41, 4976-4987. doi: 10.1093/nar/gkt182

Liu, Y., Zhang, M., Liang, L., Li, J., and Chen, Y. X. (2015). Over-expression of IncRNA DANCR is associated with advanced tumor progression and poor prognosis in patients with colorectal cancer. Int. J. Clin. Exp. Pathol. 8, $11480-11484$.

Mercer, T. R., and Mattick, J. S. (2013). Structure and function of long noncoding RNAs in epigenetic regulation. Nat. Struct. Mol. Biol. 20, 300-307. doi: 10.1038/nsmb. 2480

Mourtada-Maarabouni, M., Hasan, A. M., Farzaneh, F., and Williams, G. T. (2010). Inhibition of human T-cell proliferation by mammalian target of rapamycin (mTOR) antagonists requires noncoding RNA growth-arrest-specific transcript 5 (GAS5). Mol. Pharmacol. 78, 19-28. doi: 10.1124/mol.110.064055

Mourtada-Maarabouni, M., Hedge, V. L., Kirkham, L., Farzaneh, F., and Williams, G. T. (2008). Growth arrest in human T-cells is controlled by the non-coding RNA growth-arrest-specific transcript 5 (GAS5). J. Cell Sci. 121, 939-946. doi: $10.1242 /$ jcs. 024646

Mourtada-Maarabouni, M., Pickard, M. R., Hedge, V. L., Farzaneh, F., and Williams, G. T. (2009). GAS5, a non-protein-coding RNA, controls apoptosis and is downregulated in breast cancer. Oncogene 28, 195-208. doi: 10.1038/onc.2008.373

Ni, B., Yu, X., Guo, X., Fan, X., Yang, Z., Wu, P., et al. (2015). Increased urothelial cancer associated 1 is associated with tumor proliferation and metastasis and predicts poor prognosis in colorectal cancer. Int. J. Oncol. 47, 1329-1338. doi: 10.3892/ijo.2015.3109

Nie, L., Wu, H. J., Hsu, J. M., Chang, S. S., Labaff, A. M., Li, C. W., et al. (2012). Long non-coding RNAs: versatile master regulators of gene expression and crucial players in cancer. Am. J. Transl. Res. 4, 127-150.

Nissan, A., Stojadinovic, A., Mitrani-Rosenbaum, S., Halle, D., Grinbaum, R., Roistacher, M., et al. (2012). Colon cancer associated transcript-1: a novel RNA expressed in malignant and pre-malignant human tissues. Int. J. Cancer 130, 1598-1606. doi: 10.1002/ijc.26170

Nugent, M., Miller, N., and Kerin, M. J. (2011). MicroRNAs in colorectal cancer: function, dysregulation and potential as novel biomarkers. Eur. J. Surg. Oncol. 37, 649-654. doi: 10.1016/j.ejso.2011.05.005

Pickard, M. R., Mourtada-Maarabouni, M., and Williams, G. T. (2013). Long noncoding RNA GAS5 regulates apoptosis in prostate cancer cell lines. Biochim. Biophys. Acta 1832, 1613-1623. doi: 10.1016/j.bbadis.2013.05.005

Pino, M. S., and Chung, D. C. (2010). The chromosomal instability pathway in colon cancer. Gastroenterology 138, 2059-2072. doi: 10.1053/j.gastro.2009.12.065

Ponting, C. P., Oliver, P. L., and Reik, W. (2009). Evolution and functions of long noncoding RNAs. Cell 136, 629-641. doi: 10.1016/j.cell.2009.02.006

Popat, S., Hubner, R., and Houlston, R. S. (2005). Systematic review of microsatellite instability and colorectal cancer prognosis. J. Clin. Oncol. 23, 609-618. doi: 10.1200/JCO.2005.01.086

Prensner, J. R., Iyer, M. K., Balbin, O. A., Dhanasekaran, S. M., Cao, Q., Brenner, J. C., et al. (2011). Transcriptome sequencing across a prostate cancer cohort identifies PCAT-1, an unannotated lincRNA implicated in disease progression. Nat. Biotechnol. 29, 742-749. doi: 10.1038/nbt.1914

Prensner, J. R., Sahu, A., Iyer, M. K., Malik, R., Chandler, B., Asangani, I. A., et al. (2014). The IncRNAs PCGEM1 and PRNCR1 are not implicated in castration resistant prostate cancer. Oncotarget 5, 1434-1438. doi: 10.18632/oncotarget.1846

Qi, P., Xu, M. D., Ni, S. J., Huang, D., Wei, P., Tan, C., et al. (2013). Low expression of LOC285194 is associated with poor prognosis in colorectal cancer. J. Transl. Med. 11:122. doi: 10.1186/1479-5876-11-122

Qi, P., Xu, M. D., Ni, S. J., Shen, X. H., Wei, P., Huang, D., et al. (2015). Downregulation of ncRAN, a long non-coding RNA, contributes to colorectal cancer cell migration and invasion and predicts poor overall survival for colorectal cancer patients. Mol. Carcinog. 54, 742-750. doi: 10.1002/mc.22137

Qiao, H. P., Gao, W. S., Huo, J. X., and Yang, Z. S. (2013). Long non-coding RNA GAS5 functions as a tumor suppressor in renal cell carcinoma. Asian Pac. J. Cancer Prev. 14, 1077-1082. doi: 10.7314/APJCP.2013.14.2.1077
Qiu, J. J., and Yan, J. B. (2015). Long non-coding RNA LINC01296 is a potential prognostic biomarker in patients with colorectal cancer. Tumour Biol. 36, 7175-7183. doi: 10.1007/s13277-015-3448-5

Qiu, M., Xu, Y., Yang, X., Wang, J., Hu, J., Xu, L., et al. (2014). CCAT2 is a lung adenocarcinoma-specific long non-coding RNA and promotes invasion of non-small cell lung cancer. Tumour Biol. 35, 5375-5380. doi: 10.1007/s13277014-1700-z

Ragusa, M., Barbagallo, C., Statello, L., Condorelli, A. G., Battaglia, R., Tamburello, L., et al. (2015). Non-coding landscapes of colorectal cancer. World J. Gastroenterol. 21, 11709-11739. doi: 10.3748/wjg.v21.i41.11709

Redis, R. S., Sieuwerts, A. M., Look, M. P., Tudoran, O., Ivan, C., Spizzo, R., et al. (2013). CCAT2, a novel long non-coding RNA in breast cancer: expression study and clinical correlations. Oncotarget 4, 1748-1762. doi: 10.18632/oncotarget.1292

Ren, Y., Xiao, Y., Wan, X., Zhao, Y., Li, J., Li, Y., et al. (2015). Association of long non-coding RNA HOTTIP with progression and prognosis in colorectal cancer. Int. J. Clin. Exp. Pathol. 8, 11458-11463.

Rinn, J. L., Kertesz, M., Wang, J. K., Squazzo, S. L., Xu, X., Brugmann, S. A., et al. (2007). Functional demarcation of active and silent chromatin domains in human HOX loci by noncoding RNAs. Cell 129, 1311-1323. doi: 10.1016/j.cell.2007.05.022

Rui, Y. Y., Zhang, D., Zhou, Z. G., Wang, C., Yang, L., Yu, Y. Y., et al. (2013). Can K-ras gene mutation be utilized as prognostic biomarker for colorectal cancer patients receiving chemotherapy? A meta-analysis and systematic review. PLoS ONE 8:e77901. doi: 10.1371/journal.pone.0077901

Salazar, R., Roepman, P., Capella, G., Moreno, V., Simon, I., Dreezen, C., et al. (2011). Gene expression signature to improve prognosis prediction of stage II and III colorectal cancer. J. Clin. Oncol. 29, 17-24. doi: 10.1200/JCO.2010.30.1077

Sanz-Pamplona, R., Berenguer, A., Cordero, D., Riccadonna, S., Sole, X., Crous-Bou, M., et al. (2012). Clinical value of prognosis gene expression signatures in colorectal cancer: a systematic review. PLOS ONE 7:e48877. doi: 10.1371/journal.pone.0048877

Sasaki, Y. T. F., Sano, M., Kin, T., Asai, K., and Hirose, T. (2007). Coordinated expression of ncRNAs and HOX mRNAs in the human HOXA locus. Biochem. Biophys. Res. Commun. 357, 724-730. doi: 10.1016/j.bbrc.2007.03.200

Schneider, C., King, R. M., and Philipson, L. (1988). Genes specifically expressed at growth arrest of mammalian cells. Cell 54, 787-793. doi: 10.1016/S00928674(88)91065-3

Shi, D., Zheng, H., Zhuo, C., Peng, J., Li, D., Xu, Y., et al. (2014). Low expression of novel lncRNA RP11-462C24.1 suggests a biomarker of poor prognosis in colorectal cancer. Med. Oncol. 31:31. doi: 10.1007/s12032-014-0031-7

Shi, W. H., Wu, Q. Q., Li, S. Q., Yang, T. X., Liu, Z. H., Tong, Y. S., et al. (2015). Upregulation of the long noncoding RNA PCAT-1 correlates with advanced clinical stage and poor prognosis in esophageal squamous carcinoma. Tumour Biol. 36, 2501-2507. doi: 10.1007/s13277-014-2863-3

Shtivelman, E., and Bishop, J. M. (1989). The PVT gene frequently amplifies with MYC in tumor cells. Mol. Cell. Biol. 9, 1148-1154. doi: 10.1128/MCB.9.3.1148

Smolle, M., Uranitsch, S., Gerger, A., Pichler, M., and Haybaeck, J. (2014). Current status of long non-coding RNAs in human cancer with specific focus on colorectal cancer. Int. J. Mol. Sci. 15, 13993-14013. doi: 10.3390/ijms1508 13993

Sun, J., Ding, C., Yang, Z., Liu, T., Zhang, X., Zhao, C., et al. (2016). The long non-coding RNA TUG1 indicates a poor prognosis for colorectal cancer and promotes metastasis by affecting epithelial-mesenchymal transition. J. Trans. Med. BioMed Central 14:42. doi: 10.1186/s12967-016-0786-z

Svoboda, M., Slyskova, J., Schneiderova, M., Makovicky, P., Bielik, L., Levy, M., et al. (2014). HOTAIR long non-coding RNA is a negative prognostic factor not only in primary tumors, but also in the blood of colorectal cancer patients. Carcinogenesis 35, 1510-1515. doi: 10.1093/carcin/bgu055

Szafron, L. M., Balcerak, A., Grzybowska, E. A., Pienkowska-Grela, B., Podgorska, A., Zub, et al. (2015). The putative oncogene, CRNDE, is a negative prognostic factor in ovarian cancer patients. Oncotarget 6, 43897-43910. doi: 10.18632/oncotarget.6016

Takahashi, Y., Sawada, G., Kurashige, J., Uchi, R., Matsumura, T., Ueo, H., et al. (2014). Amplification of PVT-1 is involved in poor prognosis via apoptosis inhibition in colorectal cancers. Br. J. Cancer 110, 164-171. doi: 10.1038/bjc.2013.698 
Tong, Y. S., Zhou, X. L., Wang, X. W., Wu, Q. Q., Yang, T. X., Lv, J., et al. (2014). Association of decreased expression of long non-coding RNA LOC285194 with chemoradiotherapy resistance and poor prognosis in esophageal squamous cell carcinoma. J. Transl. Med. 12:233. doi: 10.1186/s12967-014-0233-y

Tseng, Y. Y., Moriarity, B. S., Gong, W., Akiyama, R., Tiwari, A., Kawakami, H., et al. (2014). PVT1 dependence in cancer with MYC copy-number increase. Nature 512, 82-86. doi: 10.1038/nature13311

Ulitsky, I., and Bartel, D. P. (2013). lincRNAs: genomics, evolution, and mechanisms. Cell 154, 26-46. doi: 10.1016/j.cell.2013.06.020

Wang, C. Y., Hua, L., Yao, K. H., Chen, J. T., Zhang, J. J., and Hu, J. H. (2015). Long non-coding RNA CCAT2 is up-regulated in gastric cancer and associated with poor prognosis. Int. J. Clin. Exp. Pathol. 8, 779-785.

Wang, J., Liu, D., Zhou, W., Wang, M., Xia, W., and Tang, Q. (2014). Prognostic value of matrix metalloprotease-1/protease-activated receptor-1 axis in patients with prostate cancer. Med. Oncol. 31:968. doi: 10.1007/s12032-0140968-6

Wang, K. C., Yang, Y. W., Liu, B., Sanyal, A., Corces-Zimmerman, R., Chen, Y., et al. (2011). A long noncoding RNA maintains active chromatin to coordinate homeotic gene expression. Nature 472, 120-124. doi: 10.1038/nature09819

Wang, X. S., Zhang, Z., Wang, H. C., Cai, J. L., Xu, Q. W., Li, M. Q., et al. (2006). Rapid identification of UCA1 as a very sensitive and specific unique marker for human bladder carcinoma. Clin. Cancer Res. 12, 4851-4858. doi: 10.1158/1078-0432.CCR-06-0134

Wang, Y., Wang, Y., Li, J., Zhang, Y., Yin, H., and Han, B. (2015). CRNDE, a longnoncoding RNA, promotes glioma cell growth and invasion through mTOR signaling. Cancer Lett. 367, 122-128. doi: 10.1016/j.canlet.2015.03.027

Wapinski, O., and Chang, H. Y. (2011). Long noncoding RNAs and human disease. Trends Cell Biol. 21, 354-361. doi: 10.1016/j.tcb.2011.04.001

Wu, Y., Lu, W., Xu, J., Shi, Y., Zhang, H., and Xia, D. (2015). Prognostic value of long non-coding RNA MALAT1 in cancer patients. Tumour Biol. doi: 10.1007/s13277-015-3870-8. [Epub ahead of print].

Wu, Y., Zhang, L., Wang, Y., Li, H., Ren, X., Wei, F., et al. (2014). Long noncoding RNA HOTAIR involvement in cancer. Tumour Biol. 35, 9531-9538. doi: 10.1007/s13277-014-2523-7

Wu, Z. H., Wang, X. L., Tang, H. M., Jiang, T., Chen, J., Lu, S., et al. (2014). Long non-coding RNA HOTAIR is a powerful predictor of metastasis and poor prognosis and is associated with epithelial-mesenchymal transition in colon cancer. Oncol. Rep. 32, 395-402. doi: 10.3892/or.2014.3186

Xiang, J. F., Yin, Q. F., Chen, T., Zhang, Y., Zhang, X. O., Wu, Z., et al. (2014). Human colorectal cancer-specific CCAT1-L lncRNA regulates longrange chromatin interactions at the MYC locus. Cell Res. 24, 513-531. doi: $10.1038 / \mathrm{cr} .2014 .35$

Xie, X., Tang, B., Xiao, Y. F., Xie, R., Li, B. S., Dong, H., et al. (2015). Long non-coding RNAs in colorectal cancer. Oncotarget 7, 5226-5239. doi: 10.18632/oncotarget.6446

Xu, C., Yang, M., Tian, J., Wang, X., and Li, Z. (2011). MALAT-1: a long non-coding RNA and its important $3^{\prime}$ end functional motif in colorectal cancer metastasis. Int. J. Oncol. 39, 169-175. doi: 10.3892/ijo.2011.1007

Yan, B., Gu, W., Yang, Z., Gu, Z., Yue, X., Gu, Q., et al. (2014). Downregulation of a long noncoding RNA-ncRuPAR contributes to tumor inhibition in colorectal cancer. Tumour Biol. 35, 11329-11335. doi: 10.1007/s13277-014-2465-0

Yang, M. H., Hu, Z. Y., Xu, C., Xie, L. Y., Wang, X. Y., Chen, S. Y., et al. (2015). MALAT1 promotes colorectal cancer cell proliferation/migration/invasion via PRKA kinase anchor protein 9. Biochim. Biophys. Acta 1852, 166-174. doi: 10.1016/j.bbadis.2014.11.013

Ye, L. C., Ren, L., Qiu, J. J., Zhu, D. X., Chen, T., Chang, W. J., et al. (2015). Aberrant expression of long noncoding RNAs in colorectal cancer with liver metastasis. Tumour Biol. 36, 8747-8754. doi: 10.1007/s13277-015-3627-4

Yin, D. D., Liu, Z. J., Zhang, E., Kong, R., Zhang, Z. H., and Guo, R. H. (2015). Decreased expression of long noncoding RNA MEG3 affects cell proliferation and predicts a poor prognosis in patients with colorectal cancer. Tumour Biol. 36, 4851-4859. doi: 10.1007/s13277-015-3139-2

Yin, D., He, X., Zhang, E., Kong, R., De, W., and Zhang, Z. (2014). Long noncoding RNA GAS5 affects cell proliferation and predicts a poor prognosis in patients with colorectal cancer. Med. Oncol. 31, 253. doi: 10.1007/s12032-0140253-8
Young, T., Matsuda, T., and Cepko, C. (2005). The noncoding RNA taurine upregulated gene 1 is required for differentiation of the murine retina. Curr. Biol. 15, 501-512. doi: 10.1016/j.cub.2005.02.027

Yu, M., Ohira, M., Li, Y., Niizuma, H., Oo, M. L., Zhu, Y., et al. (2009). High expression of ncRAN, a novel non-coding RNA mapped to chromosome $17 \mathrm{q} 25.1$, is associated with poor prognosis in neuroblastoma. Int. J. Oncol. 34, 931-938. doi: 10.3892/ijo_00000219

Yuan, J. H., Yang, F., Wang, F., Ma, J. Z., Guo, Y. J., Tao, Q. F., et al. (2014). A long noncoding RNA activated by TGF-beta promotes the invasionmetastasis cascade in hepatocellular carcinoma. Cancer Cell 25, 666-681. doi: 10.1016/j.ccr.2014.03.010

Yuan, S. X., Wang, J., Yang, F., Tao, Q. F., Zhang, J., Wang, L. L., et al. (2016). Long noncoding RNA DANCR increases stemness features of hepatocellular carcinoma by derepression of CTNNB1. Hepatology 63, 499-511. doi: 10.1002/hep. 27893

Zanke, B. W., Greenwood, C. M., Rangrej, J., Kustra, R., Tenesa, A., Farrington, S. M., et al. (2007). Genome-wide association scan identifies a colorectal cancer susceptibility locus on chromosome 8q24. Nat. Genet. 39, 989-994. doi: $10.1038 /$ ng2089

Zhang, K., Shi, Z. M., Chang, Y. N., Hu, Z. M., Qi, H. X., and Hong, W. (2014). The ways of action of long non-coding RNAs in cytoplasm and nucleus. Gene 547, 1-9. doi: 10.1016/j.gene.2014.06.043

Zhang, Q., Geng, P.-L., Yin, P., Wang, X.-L., Jia, J.-P., and Yao, J. (2013). Down-regulation of long non-coding RNA TUG1 inhibits osteosarcoma cell proliferation and promotes apoptosis. Asian Pac. J. Cancer Prev. 14, 2311-2315. doi: 10.7314/APJCP.2013.14.4.2311

Zhang, S., Chen, S., Yang, G., Gu, F., Li, M., Zhong, B., et al. (2014). Long noncoding RNA HOTAIR as an independent prognostic marker in cancer: a meta-analysis. PLoS ONE 9:e105538. doi: 10.1371/journal.pone.0063516

Zhang, X., Xu, Y., He, C., Guo, X., Zhang, J., He, C., et al. (2015). Elevated expression of CCAT2 is associated with poor prognosis in esophageal squamous cell carcinoma. J. Surg. Oncol. 111, 834-839. doi: 10.1002/jso.23888

Zhang, X., Zhou, Y., Mehta, K. R., Danila, D. C., Scolavino, S., Johnson, S. R., et al. (2003). A pituitary-derived MEG3 isoform functions as a growth suppressor in tumor cells. J. Clin. Endocrinol. Metab. 88, 5119-5126. doi: 10.1210/jc.2003-030222

Zhao, W., Song, M., Zhang, J., Kuerben, M., and Wang, H. (2015). Combined identification of long non-coding RNA CCAT1 and HOTAIR in serum as an effective screening for colorectal carcinoma. Int. J. Clin. Exp. Pathol. 8, 14131-14140.

Zheng, H. T., Shi, D. B., Wang, Y. W., Li, X. X., Xu, Y., Tripathi, P., et al. (2014). High expression of lncRNA MALAT1 suggests a biomarker of poor prognosis in colorectal cancer. Int. J. Clin. Exp. Pathol. 7, 3174-3181.

Zhou, Y., Zhang, X., and Klibanski, A. (2012). MEG3 noncoding RNA: a tumor suppressor. J. Mol. Endocrinol. 48, R45-R53. doi: 10.1530/jme-12-0008

Zhou, Y., Zhong, Y., Wang, Y., Zhang, X., Batista, D. L., Gejman, R., et al. (2007). Activation of p53 by MEG3 non-coding RNA. J. Biol. Chem. 282, 24731-24742. doi: 10.1074/jbc.M702029200

Zhu, L., and Xu, P. C. (2013). Downregulated LncRNA-ANCR promotes osteoblast differentiation by targeting EZH2 and regulating Runx2 expression, Biochem. Biophys. Res. Commun. 432, 612-617. doi: 10.1016/j.bbrc.2013.02.036

Zhu, Y., Yu, M., Li, Z., Kong, C., Bi, J., Li, J., et al. (2011). ncRAN, a newly identified long noncoding RNA, enhances human bladder tumor growth, invasion, and survival. Urology 77, 510 e511-515. doi: 10.1016/j.urology.2010.09.022

Conflict of Interest Statement: The authors declare that the research was conducted in the absence of any commercial or financial relationships that could be construed as a potential conflict of interest.

Copyright (c) 2016 Saus, Brunet-Vega, Iraola-Guzmán, Pegueroles, Gabaldón and Pericay. This is an open-access article distributed under the terms of the Creative Commons Attribution License (CC BY). The use, distribution or reproduction in other forums is permitted, provided the original author(s) or licensor are credited and that the original publication in this journal is cited, in accordance with accepted academic practice. No use, distribution or reproduction is permitted which does not comply with these terms. 